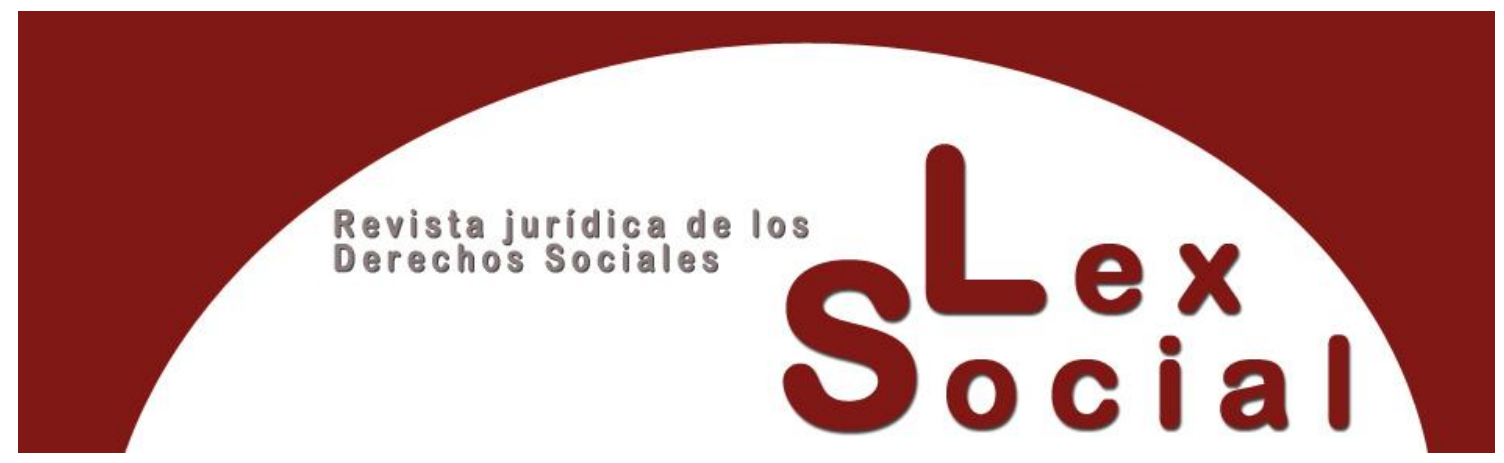

\title{
LA AUTODETERMINACIÓN DE GÉNERO EN EL ÁMBITO EDUCATIVO: MECANISMOS DE IMPLEMENTACIÓN EN LAS UNIVERSIDADES
}

\section{GENDER SELF-DETERMINATION IN THE EDUCATIONAL FIELD: IMPLEMENTATION MECHANISMS IN UNIVERSITIES}

\author{
REYES MARZAL RAGA \\ Profesora Titular de Derecho administrativo \\ Universitat de València \\ https://orcid.org/0000-0002-7972-7709
}

Cómo citar este trabajo: Marzal Raga, R. (2021). La autodeterminación de género en el ámbito educativo: mecanismos de implementación en las universidades. Lex Social, Revista De Derechos Sociales, 11 (2), 248-288. https://doi.org/10.46661/lexsocial.5953

\begin{abstract}
RESUMEN
El derecho de autodeterminación de género tiene importantes implicaciones en el desarrollo del derecho a la educación y muy concretamente en el ámbito universitario. El estudio analiza, en primer lugar, las dificultades que afronta el reconocimiento del derecho de autodeterminación de género y el impulso que la legislación autonómica ha supuesto para superar el inicial enfoque antidiscriminatorio, en favor de un concepto jurídico-constitucional de identidad desarrollada con plena libertad. Después se analiza cuál es la posición de las Universidades y qué mecanismos tienen para garantizar la tutela integral de la identidad de género, con especial atención a las Universidades de la Comunitat Valenciana.
\end{abstract}

\section{(cc) BY-NC-SA}


Palabras Clave: Reconocimiento del derecho de identidad de género, Tutela antidiscriminatoria, Intervención administrativa en la educación, Protocolos administrativos, Potestad reglamentaria, Universidades.

\begin{abstract}
The right to gender self-determination has important implications in the development of the right to education and very specifically in the university sphere. The study analyzes, in the first place, the difficulties faced by the recognition of the right to gender self-determination and the impulse that the regional legislation has supposed to overcome the initial anti-discrimination approach, in favor of a legalconstitutional concept of identity developed with full freedom. Afterwards, the position of the Universities is analyzed and what mechanisms they have to guarantee the integral protection of gender identity, with special attention to the Universities of the Comunitat Valenciana.
\end{abstract}

KEYWORDS: Recognition of the right to gender identity, Anti-discrimination protection, Administrative intervention in education, Administrative protocols, Regulatory authority, Universities.

SUMARIO

I.- LA AUTODETERMINACIÓN DE GÉNERO: DE LA TUTELA ANTIDISCRIMINATORIA AL CONCEPTO JURÍDICO-CONSTITUCIONAL DE IDENTIDAD DESARROLLADA CON PLENA LIBERTAD

1.- La superación del enfoque antidiscriminatorio

2.- El derecho de autodeterminación de género en la legislación estatal y autonómica

2.1. El marco normativo estatal

2.2. El marco autonómico

3.- El reconocimiento del derecho de autodeterminación de género en la legislación valenciana

II.- LA TUTELA DE LA AUTODETERMINACIÓN DE GÉNERO A TRAVÉS DE LA INTERVENCIÓN EN MATERIA EDUCATIVA

1.- Los mecanismos de la legislación autonómica para la tutela integral

1.1.- La elaboración de un protocolo de atención educativa a la identidad de género

1.2.- La adopción de medidas de ordenación académica

1.3.- La formación de la comunidad educativa no universitaria 
1.4.- La coordinación entre las áreas de educación, sanidad y servicios sociales

2.- La posición de las Universidades valencianas para la efectividad del derecho de autodeterminación de género

2.1.- La adaptación del Protocolo de atención educativa a la identidad de género por parte de las Universidades valencianas

2.2.- Ámbitos sobre los que debe proyectarse la adaptación del Protocolo autonómico

2.2.1.- Adaptaciones subjetivas: La comunidad universitaria

2.2.2.- Adaptación material del Protocolo

2.2.3.- Adaptación procedimental

2.3.- El deber de colaboración

CONCLUSIONES

BIBLIOGRAFÍA

\section{I.- La autodeterminación de género: De la tutela antidiscriminatoria al concepto jurídico-constitucional de identidad desarrollada con plena libertad}

\section{1.- La superación del enfoque antidiscriminatorio}

En nuestro ordenamiento, la tutela de la identidad de género ha encontrado encaje constitucional en la cláusula antidiscriminatoria del artículo $14 \mathrm{CE}$ desde los primeros momentos del Estado constitucional, aunque el tratamiento normativo del sexo no se agota en la tutela antidiscriminatoria sino que es más amplio, comprendiendo también el derecho de las personas a ser tratadas por toda la sociedad conforme a su identidad sexual $^{1}$. En efecto, aunque el artículo $14 \mathrm{CE}$ no contiene una referencia explícita a la discriminación derivada de la expresión sexual, orientación sexual, identidad sexual o identidad de género, éstas son circunstancias incluidas en la oración "cualquier otra condición o circunstancia personal o social", a la que debe ser referida la interdicción de la discriminación ${ }^{2}$. Tal como reconoce el Tribunal Constitucional, la prohibición de

\footnotetext{
${ }^{1}$ En relación con el papel del Estado en el reconocimiento de la identidad sexual, MALDONADO, J., "El reconocimiento del derecho a la identidad sexual de los menores transexuales en los ámbitos registral, educativo y sanitario", Revista Jurídica de la Universidad Autónoma de Madrid, 36, 2017-II, pp. 150-151, señala que no se agota en el derecho a ser reconocido como hombre o mujer (o ambos, o como ni hombre o mujer en el caso de las personas no binarias) por el Estado (reconocimiento jurídico de la identidad sexual) a través del Registro Civil, sino que es más amplio, comprendiendo también el derecho de las personas a ser tratadas por toda la sociedad conforme a su identidad sexual (tratamiento conforme a la identidad sexual), algo que debe garantizar el Estado.

${ }^{2}$ Apunta VILLALBA SÁNCHEZ, A., "Los protocolos de prevención y actuación frente al acoso por razón de género en las universidades pertenecientes a la Comunidad Autónoma de Galicia", Dereito, Vol. 28, 1, 2019, pp. 179-207, el sexo hizo su aparición en el ordenamiento jurídico español como causa de la conducta discriminatoria articulada a través del acoso. El artículo 7.2 de la Ley Orgánica 3/2007, de 22 de marzo, para la igualdad efectiva de mujeres y hombres se refiere al acceso al empleo, a la formación y promoción
} 
discriminación por razón de identidad de género se encuentra implícita en la expresión "circunstancias personales y sociales" a que se refiere el artículo 14 CE (STC 166/1988, $41 / 2006$ y 176/2008) $)^{3}$. Pero junto a este claro enfoque antidiscriminatorio, la CE contiene otros preceptos que pueden contribuir a la conformación de la autodeterminación de género como un derecho con sustantividad propia, configurado a partir del equilibrio entre derechos y principios constitucionales, y no sólo porque "lo requieren los tiempos" sino porque así lo exigen los valores y principios de nuestro Estado constitucional democrático de Derecho ${ }^{4}$. La dignidad de la persona y el libre desarrollo de la personalidad, reconocidos en el artículo $10 \mathrm{CE}$ como fundamento del orden político y de la paz, sirven de soporte constitucional para el desarrollo del derecho de autodeterminación de género y para aportar soluciones al problema de la llamada identidad de género, aunque no faltan voces en contra de la aplicación de este precepto ${ }^{5}$. Asimismo, la identidad sexual, como parte de un derecho más amplio de identidad personal ${ }^{6}$, encuentra acomodo constitucional en el seno de otros muchos derechos fundamentales como el derecho a la integridad física y moral y a no sufrir tratos inhumanos o degradantes reconocido en el artículo $15 \mathrm{CE}$; o el derecho al honor, la intimidad personal y a la propia imagen (artículo $18 \mathrm{CE}$ ), pero también en los derechos reconocidos constitucionalmente como principios rectores de la política social y económica, entre los cuales se encuentran el derecho a contraer matrimonio (artículo $32 \mathrm{CE}$ ), el derecho al trabajo (artículo $35 \mathrm{CE}$ ) o el derecho a la salud (artículo $43 \mathrm{CE}$ ).

profesionales, y a las condiciones de trabajo, para obtener una mención al acoso debido al sexo, como factor de discriminación. Pero, a juicio de la autora, esta norma se centra en el sexo como factor de diferenciación, lo cual deja fuera de su ámbito de protección aquellos supuestos donde la violencia obedece a la orientación sexual de la víctima o a su identidad de género.

${ }^{3}$ Véase también el recorrido jurisprudencial que recoge SALAZAR BENÍTEZ, O., "La identidad de género como derecho emergente", Revista de Estudios Políticos, 169, 2015, pp. 82-85, señalando la posición inicial del Tribunal Supremo y las posteriores aportaciones del Tribunal Constitucional, muy concretamente la inclusión de la "identidad de género" dentro de las "circunstancias personales y sociales" a que se refiere el artículo 14 CE al prohibir tratos discriminatorios (STC 176/2008).

${ }^{4}$ Como señala ARAGON REYES, M., "Nota Introductoria", Revista General de Derecho Constitucional, 17,2013 , p. 2, el Derecho tiene que garantizar la no discriminación por motivos de sexo u orientación sexual, así como aportar soluciones al problema de la llamada identidad de género (aunque sería más correcto en nuestro idioma denominarla identidad de sexo, creo yo). Y ello no sólo porque "lo requieran los tiempos", sino, sobre todo, porque lo requieren un valor y un principio que son básicos en un Estado constitucional democrático de Derecho: la dignidad de la persona y el libre desarrollo de la personalidad, que, además, en España se encuentran positivados en el artículo 10.1 de la Constitución.

5 ARAGON REYES, M., "Nota...”, p. 2, sostiene la aplicación del artículo 10 CE para aportar soluciones al problema de la llamada identidad de género. Por su parte, BELDA PÉREZ-PEDRERO, E., "Transexualidad y Derechos Fundamentales: protección integral sin la utilización del factor sexo como diferencia”, Cuadernos de Derecho Público, 21, 2004, p. 139, señala que ese derecho se construye a partir de varias pautas: el libre desarrollo de la personalidad, la integridad moral, la intimidad y la libertad de pensamiento, incluso la propia imagen, estarían, probablemente, presentes. En contra de la utilización del artículo $10 \mathrm{CE}$ para formular una concepción jurídica de la transexualidad se muestra NANCLARES VALLE, J., "Comentario a la Sentencia del Tribunal Supremo de 6 de septiembre de 2002: una recepción incompleta de la nueva doctrina del Tribunal Europeo de Derechos Humanos en materia de transexualidad", Repertorio Aranzadi del Tribunal Constitucional, 12, 2003, pp. 2609-2644.

6 LÓPEZ-GALIACHO PERONA, J., La problemática jurídica de la transexualidad, McGraw-Hill, Madrid, 2000, p. 111. 
Toda esta amalgama de preceptos constitucionales muestra las amplias posibilidades de dar soporte constitucional a la configuración legal de un verdadero derecho de autodeterminación de género que supere el enfoque discriminatorio en favor de la plena libertad para mostrar la identidad sexual escogida, aunque la tarea no está exenta de dificultades. La indefinición y constante evolución de conceptos que se ven implicados en su diseño legislativo - comenzando por la concreción de conceptos metajurídicos tales como las expresiones "género" y "sexo" 7-, la delimitación del ámbito subjetivo sobre el que proyectar la regulación, que se formula a partir de muy distintos y cambiantes conceptos (lesbianas, gays, trans, bisexuales, intersexuales, transgénero, personas con variaciones intersexuales o con diferencias del desarrollo sexual, expresión de género no normativa, o desarrollo sexual no binario), la identificación de los títulos competenciales que se ven implicados en esta materia y la consecuente atribución decisoria en favor de unos u otros centros de poder y, sin duda, el componente político y sociocultural que subyace en las cuestiones vinculadas al sexo, son sólo algunos de los inconvenientes que deben superarse para la conformación de un marco normativo que garantice la tutela integral de las personas trans a partir del libre ejercicio de su identidad.

En esta tarea, el legislador cuenta con importantes textos internacionales suscritos por España - y por tanto integrantes del ordenamiento interno (artículo $96 \mathrm{CE}$ )-, así como con otras disposiciones internacionales de calado, entre las que merece atención la formulación de los Principios de Yogyakarta ${ }^{8}$, y con el acervo europeo impulsado por el Tratado de Lisboa ${ }^{9}$, en especial el posicionamiento de la Comisión Europea a través de la

\footnotetext{
${ }^{7}$ Sobre las nociones de "sexo" y "género" puede consultarse el Informe temático. Identidad de Género y Derechos Humanos, elaborado por el Comisario para los Derechos Humanos del Consejo de Europa, con fecha 29 de julio de 2009 (accesible desde https://wcd.coe.int/ViewDoc.jsp?id=1476365. Introducción. p. 5. Ultimo acceso, diciembre 2020), de acuerdo con el cual, el término "sexo" se refiere a las diferencias biológicas entre mujeres y hombres, mientras que "género" también incluye el aspecto social de la diferencia entre los géneros, en adición al elemento biológico. En relación con la formulación de propuestas queer, véase MONEREO ATIENZA, C., "Aproximación conceptual a la orientación sexual e identidad de género: Estrategias político-jurídicas para la reivindicación de derechos del colectivo de LGBT", Aportaciones a la investigación sobre mujeres y género: $V$ Congreso Universitario Internacional "Investigación y Género, Sevilla, 3 y 4 de julio de 2014, 2015, pp. 1231-1248 (accesible desde https://idus.us.es/handle/11441/41135. Último acceso, diciembre 2020). Sobre las repercusiones semánticas de la distinción, GARCÍA MESEGUER, A., "Género y sexo en el nuevo Diccionario de la Real Academia", Política científica, $\mathrm{n}^{\circ}$ 37, 1993, pp. 51-56. Un enfoque interdisciplinar de los términos sexo y género, en la obra colectiva Del sexo al género: los equívocos de un concepto, TUBERT, S., Cátedra, 2003. ${ }_{8}^{8}$ Principios sobre la aplicación de la legislación internacional de derechos humanos en relación con la orientación sexual y la identidad de género, adoptados por el Panel Internacional de Especialistas en Legislación Internacional de Derechos Humanos y en orientación sexual e identidad de género. Indonesia, 6-9 de noviembre de 2006. Respecto del valor normativo que pueden tener los Principios de Yogyakarta, ELVIRA PERALES, A., "Transexualidad y Derechos", Revista General de Derecho Constitucional, 17, 2013, pp. 1-7, apunta que ante la ausencia de Tratado en que se integren estos principios, hay voces que proclaman que podría otorgarse a dichos Principios la consideración de costumbre internacional.

${ }^{9}$ El proceso de construcción jurídica de la identidad de género y de la orientación sexual en la Unión Europea y el impacto del Tratado de Lisboa en su consolidación puede consultarse en DÍAZ LAFUENTE, J., "La protección de los Derechos fundamentales frente a la discriminación por motivos de orientación sexual e identidad de género en la Unión Europea”, Revista General de Derecho Constitucional, 17, 2013. Sobre el papel de las Naciones Unidas en la creación y desarrollo de un derecho a la no discriminación por orientación sexual e identidad de género, ALVAREZ RODRIGUEZ, I., "La Organización de las Naciones
} 

LGBTIQ 2020-2025 ${ }^{10}$. En este documento, la Comisión aborda las desigualdades y los desafíos que afectan a estas personas, sobre todo tras la Covid-19, instando a los Estados miembro la aprobación de legislaciones basadas en el principio de autodeterminación de género, en sintonía con lo dispuesto en la Resolución 2048 (2015) de la Asamblea Parlamentaria del Consejo de Europa (Discriminación contra las personas transgénero en Europa $)^{11}$ y en los Principios de Yogyakarta. Algunos países de la UE ya han implementado en su totalidad este principio, y disponen de procedimientos administrativos para el cambio registral de nombre y sexo, basados en el principio de autodeterminación del género ${ }^{12}$. España se encuentra en un momento decisivo, con claros envites por parte de las legislaciones autonómicas, que han implementado procedimientos administrativos y prestaciones sociales de gran calado, en concreto en materia educativa; y con una reciente propuesta del Ministerio de Igualdad que, de momento, parece estar encallada ${ }^{13}$.

\section{2.- El derecho de autodeterminación de género en la legislación estatal y autonómica}

En los últimos años, la tutela que ofrece la cláusula antidiscriminatoria por razón de orientación sexual e identidad de género se ha visto mejorada tanto a nivel estatal como en la legislación autonómica, aunque algunos territorios todavía mantienen regulaciones

Unidas y el derecho a la no discriminación por motivo de orientación sexual e identidad de género: apuntes para un debate", Revista General de Derecho Constitucional, 17, 2013.

${ }^{10}$ Comunicación de la Comisión al Parlamento Europeo, al Consejo, al Comité Económico y Social Europeo y al Comité de las Regiones "Unión de la Igualdad: Estrategia para la Igualdad de las Personas LGBTIQ 2020-2025”, Bruselas, 12.11.2020 COM(2020) 698 final.

${ }^{11}$ De acuerdo con la Resolución del Consejo de Europa de 22 de abril de 2015, en lo que respecta al reconocimiento legal de género, la Asamblea exhorta a los Estados miembros a: desarrollar procedimientos rápidos, transparentes y accesibles, basados en la autodeterminación, para el cambio de nombre y sexo registrado de personas transgénero en certificados de nacimiento, cédulas de identidad, pasaportes, certificados educativos y otros documentos similares; poner estos procedimientos a disposición de todas las personas que deseen utilizarlos, independientemente de su edad, estado médico, situación económica o antecedentes policiales (apartado 6.2.1); y a abolir la esterilización y otros tratamientos médicos obligatorios, así como el diagnóstico de salud mental, como requisito legal necesario para reconocer la identidad de género de una persona en las leyes que regulan el procedimiento de cambio de nombre y género registrado (apartado 6.2.2). El texto está accesible desde la dirección electrónica: https://assembly.coe.int/nw. Último acceso, diciembre de 2020).

12 En concreto, señala la "Estrategia para la Igualdad de las Personas LGBTIQ 2020-2025", COM(2020) 698 final, que Bélgica, Dinamarca, Irlanda, Luxemburgo, Malta y Portugal (además de Noruega, Islandia y recientemente Suiza) destacan por disponer ya de procedimientos administrativos basados en el principio de autodeterminación del género. En la cola en cuanto al respeto de los derechos humanos de las personas trans están algunos países del este de Europa, con procedimientos largos, complejos y/o arbitrarios. Tras ellos se encuentran España, Austria, Eslovaquia, Estonia, Finlandia, Italia, Polonia, Reino Unido y República Checa. Estos países continúan exigiendo actuaciones médicas abusivas como la obligación de acreditar tratamientos hormonales y un diagnóstico de disforia de género.

${ }^{13}$ Como sabemos, el Ministerio de Igualdad está elaborando un Anteproyecto de Ley para la igualdad real y efectiva de las personas trans, en el que se contempla el reconocimiento del derecho de autodeterminación de género. El texto está accesible a través de la dirección electrónica: https://www.newtral.es/wpcontent/uploads/2021/02/2021-02-02_Borrador-Ley-Trans.pdf?x42453

(último acceso, diciembre de 2020). 
muy arraigadas al enfoque antidiscriminatorio y, por tanto, con pocas posibilidades de diseñar instrumentos de tutela integral de las personas trans ${ }^{14}$.

\subsection{El marco normativo estatal}

Fundamentalmente, la introducción de la referencia al sexo en nuestro ordenamiento jurídico viene de la mano del Registro Civil, que es el instrumento creado para la constancia oficial de la existencia de las personas y de su estado civil y condición. En esta tarea registral se cumple una función administrativa, aunque su ejercicio de atribuye a los órganos judiciales (artículo 86 LOPJ), que en este ámbito no actúan como órganos jurisdiccionales sino como registradores o encargados del Registro (esta es la denominación oficial) y por tanto con sujeción a las instrucciones del Ministerio de Justicia, así como a otros principios de Derecho administrativo ${ }^{15}$.

Tal como indica Ley 20/2011, de 21 de julio, del Registro Civil, las personas son identificadas por su nombre y apellidos (artículo 50), no obstante, en la inscripción de nacimiento se harán constar otras circunstancias entre las cuales se encuentra el sexo del inscrito (artículo 44), identificado tras el examen físico por parte del correspondiente facultativo, de acuerdo con el cual el Registro Civil asigna a la persona la condición de hombre o de mujer ${ }^{16}$. Se trata, pues, de un sistema de atribución binaria del género hombre/mujer, basado en las características externas de los genitales. No obstante, tras la aprobación de la Ley 3/2007, de 15 de marzo, reguladora de la rectificación registral de la mención relativa al sexo de las personas, esta asignación inicial del sexo, inamovible durante muchos años, puede ser rectificada.

En efecto, la Ley 3/2007 permite la rectificación registral del sexo de una persona en el Registro Civil cuando dicha inscripción no se corresponde con su verdadera identidad de

14 Algunas CCAA mantienen un enfoque exclusivamente antidiscriminatorio, sin un expreso reconocimiento del derecho de autodeterminación de género. Es el caso, por ejemplo, de la Ley 2/2014, de 14 de abril, por la igualdad de trato y la no discriminación de lesbianas, gays, transexuales, bisexuales e intersexuales en Galicia, cuyo artículo 1 señala como objeto de la Ley "garantizar el principio de igualdad de trato y de no discriminación por razón de orientación sexual e identidad de género de las personas homosexuales, bisexuales, transexuales, transgénero e intersexuales". De especial interés para nuestro análisis son los artículos 22 a 26, referidos a medidas específicas en el ámbito de la educación. También recurre al enfoque antidiscriminatorio la Ley 11/2014, del 10 d'octubre, per a garantir els drets de lesbianes, gais, bisexuals, transgèneres i intersexuals i per a eradicar l'homofòbia, la bifòbia i la transfobia en Cataluña, cuyo artículo 1 señala como objeto de la Ley "establecer y regular los medios y las medidas para hacer efectivo el derecho a la igualdad y a la no discriminación por razón de orientación sexual, de identidad de género o de expresión de género, en los ámbitos, tanto públicos como privados, sobre los que la Generalidad y los entes locales tienen competencias. Y la Ley balear 8/2016, de 30 de mayo, para garantizar los derechos de lesbianas, gays, trans, bisexuales e intersexuales y para erradicar la LGTBI fobia, que también contiene expresa referencia al papel de las Universidades dirigido a la aplicación de los principios de no discriminación y de respecto a la orientación sexual, la identidad de género o la expresión de género en el ámbito universitario (artículo 13).

${ }^{15}$ Sobre la naturaleza registral y no jurisdiccional del Registro civil pueden verse, entre otros, los Autos del Tribunal Constitucional de fecha 13 de diciembre de 2005 (Auto 508/2005. Cuestión de inconstitucionalidad 6661-2005, y Auto 505/2005. Cuestión de inconstitucionalidad 5856-2005), así como en el Auto 12/2008, de 16 de enero de 2008 (Cuestión de inconstitucionalidad 7796-2007).

${ }^{16}$ De acuerdo con el artículo 44.2 de la Ley 20/2011, del Registro Civil, relativa a la inscripción de nacimiento y filiación, la inscripción hace fe de del hecho, fecha, hora y lugar del nacimiento, identidad, sexo y, en su caso, filiación del inscrito. 
género, sin necesidad de operación genital, pero siempre que la persona cuente con un diagnóstico de disforia de género y se haya sometido a tratamiento hormonal durante al menos dos años (salvo que razones de salud o edad lo imposibiliten), al objeto de acomodar sus características físicas a las correspondientes al sexo reclamado. Ciertamente la Ley supone un avance en el reconocimiento del derecho de identidad de género, que no requiere de pronunciamiento judicial sino de tramitación administrativa mediante la rectificación en el correspondiente asiento del Registro Civil.

De inicio es importante destacar que el término "rectificación" utilizado en la Ley no es una expresión neutra, sino que responde al entendimiento de que no se trata de un cambio de realidades anteriores sino de una corrección/rectificación de errores ocasionados en el momento de la inscripción, debidos a la no correspondencia entre el sexo asignado o atribuido en el momento del nacimiento y la identidad de género sentida ${ }^{17}$. Con ello se ponen de manifiesto las deficiencias en la conformación del sistema registral de identificación. Se viene a reconocer así la debilidad de un mecanismo registral de atribución basado en la apariencia externa de los genitales, admitiendo explícitamente la posibilidad de error en la asignación inicial y por tanto su rectificación. Pero si llevamos esta reflexión un poco más allá, lo que se pone en cuestión no es tanto el reconocimiento de un posible error en la asignación inicial y su corrección, sino en qué medida es o no necesario incluir en la inscripción registral de las personas una expresa referencia al sexo. Un modelo como éste, que es el nuestro, responde a un entendimiento del papel de la inscripción registral más coherente con la función de identificación de la persona y no con la fehaciencia de la identidad de género, a la que responde la asignación binaria del sexo masculino/femenino ${ }^{18}$. Sin duda, la inscripción registral debe señalar los elementos necesarios para la identificación de las personas, entre los que se encuentra el nombre; pero no parece responder a esta finalidad la constancia de las circunstancias que pueden formar parte de su identidad, entre las cuales se encuentra el sexo, y cuyo componente "emocional" (por no detenernos en otros componentes), dificulta la asignación en un momento temprano como es el de la inscripción de nacimiento.

Es por ello que la doctrina afirma que la Ley 3/2007 no cambia drásticamente la tradicional forma de entender el género en nuestra sociedad ${ }^{19}$ - que como hemos dicho

\footnotetext{
${ }^{17}$ En el mismo sentido se redacta el artículo 91.2 de la Ley 20/2011, del Registro Civil, relativo a la rectificación de los asientos por procedimiento registral respecto del nombre y sexo de las personas, cuando se cumplan los requisitos del artículo 4 de la Ley 3/2007, de 15 de marzo, reguladora de la rectificación registral relativa al sexo de las personas, se rectificará mediante procedimiento registral.

18 En esta dirección, señala BELDA PÉREZ-PEDRERO, E., "Transexualidad y Derechos Fundamentales...", p. 134, que el derecho a la identidad sexual tiene un contenido consistente en la posibilidad de autodefinirse, de expresar o simplemente saber la propia condición de cada uno, aun admitiendo lo inmutable de un poso último proveniente del género con el que se nace. Por ello, señala el autor, es una identidad de carácter emocional, aunque no siempre sea o pueda ser física, rotundamente distinta de la identidad reflejada en un documento público, que no es otra cosa que identificación. Véase también FLORES SALAZAR, A. L, "El Registro Civil soporte del derecho a la identidad. Las personas trans y el reconocimiento de la identidad de género", Revista de Derecho Electoral, 25, 2018, pp. $215-231$. ${ }^{19}$ Así lo expresa SALAZAR BENÍTEZ, O., "La identidad de género como ...", p. 78, al señalar que en la Ley 3/2007 falta un tratamiento integral de las múltiples dimensiones en que las personas transexuales
} 
responde a una concepción de la igualdad de género lastradas por el sistema binario masculino/femenino ${ }^{20}$ - y mantiene el enfoque patologizante de la transexualidad ${ }^{21}$. Tampoco ofrece un tratamiento integral de las múltiples dimensiones en que las personas transexuales necesitan de instrumentos eficaces para la plena efectividad de sus derechos, por lo que se pierde la oportunidad de conformar una verdadera "ley de identidad de género", ofreciendo una regulación sectorial que no da respuesta a las disfunciones que dificultan o impiden que la igualdad de las personas trans sea real y efectiva ${ }^{22}$

En los últimos años, muchos han sido los intentos por dar respuesta a las deficiencias advertidas en las disposiciones de la Ley 3/2007, alguna de las cuales fueron resueltas por el Tribunal Constitucional al declarar la inconstitucionalidad del artículo 1.1, en la medida en que impedía la modificación registral del nombre y sexo a las personas menores de edad que tuvieren "suficiente madurez" y que se encontraren en una "situación estable de transexualidad" (STC 99/2019) $)^{23}$. Pero pese a los distintos pronunciamientos

necesitan aún de instrumentos eficaces para la plena efectividad de sus derechos; y que se trata de una norma "que no cambia drásticamente la forma de entender el sexo y el género en la sociedad".

${ }^{20}$ Para SALAZAR BENÍTEZ, O., "La identidad de género ...", p. 78, estas posiciones son deudoras de una concepción de la igualdad de género lastradas por el sistema binario masculino/femenino, propia de una visión tradicional de la sociedad marcada por una ideología de género heteronormativa, que sigue imponiendo fuertes patrones culturales en relación con las ideas dominantes de feminidad, masculinidad y el sistema sexo-género.

${ }^{21}$ Este enfoque es contrario a los Principios de Yogyakarta. En concreto, el Principio 18 reconoce que "Ninguna persona será obligada a someterse a ninguna forma de tratamiento, procedimiento o exámenes médicos o psicológicos, ni a permanecer confinada en un establecimiento médico, por motivo de su orientación sexual o su identidad de género. Con independencia de cualquier clasificación que afirme lo contrario, la orientación sexual y la identidad de género de una persona no constituyen, en sí mismas, trastornos de la salud y no deben ser sometidas a tratamiento o atención médicas, ni suprimidas".

${ }^{22}$ A juicio de ALVENTOSA DEL RIO, J., "La regulación de la identidad de género en las Comunidades Autónomas", Instituto de Derecho Iberoamericano (IDIBE), 3 de abril de 2015. Accesible desde https://idibe.org/cuestiones-de-interes-juridico/la-regulacion-de-la-identidad-de-genero-en-las-

comunidades-autonomas/ (ultimo acceso, diciembre de 2020), pese a que la Ley 3/2007 está reconociendo, en definitiva, el derecho a la identidad sexual de las personas, no se trata de una verdadera ley integral sobre la identidad de género porque, aunque la ley modifica la mención registral relativa al sexo de la persona y, a través de esta modificación se introduce una regulación sobre la identidad de la persona; ésta implica mucho más que una mera rectificación registral, de modo que se podría haber regulado de forma expresa una serie de cuestiones que se derivan del reconocimiento de la identidad de género. Entre otras, la existencia de un derecho a la propia identidad sexual y de género, la atención integral de la salud de las personas transexuales, los incentivos a la investigación en el área de la transexualidad, las campañas y acciones de lucha contra la transfobia, la creación de un servicio de asesoramiento jurídico y de apoyo psicológico y social a los familiares y allegados de la persona transexual, y el diseño de una política de discriminación positiva en el empleo y en otros ámbitos jurídicos y sociales.

${ }^{23}$ En relación con la trascendencia constitucional de esta norma, véase el Auto del Tribunal Supremo de 10 de marzo de 2016 (rec. $\mathrm{n}^{\circ} 1583 / 2015$ ), por el que se plantea cuestión de inconstitucionalidad en relación con el artículo 1.1 de la Ley 3/2007, y la STC 99/2019 que resuelve dicha cuestión declarando la inconstitucionalidad del precepto en la medida que incluye en el ámbito subjetivo de la prohibición a las personas menores de edad con "suficiente madurez" y que se encuentren en una "situación estable de transexualidad". A juicio del Tribunal Constitucional, dejar fuera del ámbito subjetivo de tal derecho a las personas menores de edad supone que a estas se les priva de la eficacia del principio constitucional del libre desarrollo de la personalidad en lo que se refiere a decidir acerca de la propia identidad. Y "esta restricción es de un grado particularmente intenso porque condiciona una manifestación de primer orden de la persona $\mathrm{y}$, consecuentemente, incide de un modo principal en su dignidad como tal individuo, cuya salvaguarda es la justificación última de un Estado constitucional como el establecido en la Constitución Española". 
jurisprudenciales ${ }^{24} \mathrm{y}$ a las múltiples propuestas normativas que los grupos parlamentarios han formulado en los últimos años, sobre todo a lo largo de la XII Legislatura ${ }^{25}$, el reconocimiento estatal del derecho de autodeterminación de género y la consecuente conformación de un régimen de tutela integral de las personas trans sigue todavía en la agenda política del Estado español ${ }^{26}$.

\subsection{El marco autonómico}

A nivel autonómico, algún Estatuto de Autonomía como el de Andalucía, ha superado el inicial enfoque antidiscriminatorio, reconociendo el derecho de toda persona a "que se respete su orientación sexual y su identidad de género" (artículo 35) ${ }^{27}$. Este

\footnotetext{
${ }^{24}$ Tras la STC 99/2019, en la que se declara que la minoría de edad no se erige en un obstáculo insalvable para poder rectificar la mención registral del sexo, siempre y cuando conste que el menor tenga la madurez suficiente y se mantenga una estabilidad en el proceso de cambio de sexo, la STS 685/2019, de 7 de diciembre de 2019 (rec. $\mathrm{n}^{\circ}$ 1583/2015) se ha pronunciado sobre el significado de la expresión "suficiente madurez del menor", remitiéndose a la definición del Comité de Derechos del Niño de la ONU, en la Observación General núm. 12 (2009) al señalar que "madurez" hace referencia a la capacidad de comprender y evaluar las consecuencias de un asunto determinado, por lo que debe tomarse en consideración al determinar la capacidad de cada niño. [...] es la capacidad de un niño para expresar sus opiniones sobre las cuestiones de forma razonable e independiente".

${ }^{25}$ Véanse las distintas proposiciones formuladas durante la XII Legislatura, en concreto, la Proposición No de Ley (PNL 161/000480), presentada por el Grupo Parlamentario Ciudadanos, relativa a la inscripción en el Registro Civil de nombres de personas cuya identidad sexual no coincide con su mención registral relativa al sexo (BOCG. Congreso de los Diputados de 11 de octubre de 2016); la Proposición de Ley (PL 122/000072), presentada por el Grupo Parlamentario Socialista, para la reforma de la Ley 3/2007, de 15 de marzo, reguladora de la rectificación registral de la mención relativa al sexo de las personas, para permitir la rectificación registral de la mención relativa al sexo y nombre de los menores transexuales y/o trans, para modificar exigencias establecidas en el artículo 4 respecto al registro del cambio de sexo, y para posibilitar medidas para mejorar la integración de las personas extranjeras residentes en España (BOCG. Congreso de los Diputados de 3 de marzo de 2017); la Proposición de Ley (PL 122/000097), presentada por el Grupo Parlamentario Confederal de Unidos Podemos-En Común Podem-En Marea, contra la discriminación por orientación sexual, identidad o expresión de género y características sexuales, y de igualdad social de lesbianas, gays, bisexuales, transexuales, transgénero e intersexuales (BOCG. Congreso de los Diputados de 12 de mayo de 2017); y la Proposición de Ley (PL 122/000191), presentada por el Grupo Parlamentario Confederal de Unidos Podemos-En Comú Podem-En Marea, sobre la protección jurídica de las personas trans y el derecho a la libre determinación de la identidad sexual y expresión de género (BOCG. Congreso de los Diputados de 2 de marzo de 2018).

En la XIII Legislatura, el Grupo Parlamentario Ciudadanos presentó la Proposición de Ley Orgánica (PL 122/000104), de igualdad social de las personas lesbianas, gais, bisexuales, transexuales, transgénero e intersexuales, de protección de la realidad trans y de no discriminación por razón de orientación sexual, identidad o expresión de género o características sexuales (BOCG. Congreso de los Diputados de 4 de diciembre 2020).

26 PLATERO MÉNDEZ, R., "Transexualidad y agenda política: una historia de (dis)continuidades y patologización", Política y sociedad. Vol. 46, n 1-2, 2018, pp. 107-128. En relación con el inadecuado marco regulatorio de la Ley 3/2007 y los problemas que se pretenden solucionar con la aprobación de una norma ley, véase el documento de Consulta Pública previa a la elaboración de un Proyecto normativo consistente en una Ley para la igualdad plena y efectiva de las personas trans, elaborado por el Ministerio de Igualdad, accesible desde https://www.igualdad.gob.es/normativa/normativa-entramitacion/Documents/ConsultaPublicaPreviaLeyIgualdadTrans.pdf (consulta, diciembre de 2020). Véase también, respecto de la problemática de los menores de edad, MALDONADO, J., "El reconocimiento del derecho a la identidad sexual ...", p. 146.

${ }^{27}$ El artículo 35 del Estatuto de Autonomía de Andalucía, aprobado por Ley Orgánica 2/2007, de 19 de marzo, de reforma del Estatuto de Autonomía para Andalucía, bajo la rúbrica "Orientación sexual" establece que: "Toda persona tiene derecho a que se respete su orientación sexual y su identidad de género. Los poderes públicos promoverán políticas para garantizar el ejercicio de este derecho".
} 
reconocimiento supone un avance en la conformación de un verdadero derecho subjetivo de autodeterminación de género, aunque el Alto Tribunal ha negado que los derechos estatutarios tengan esta consideración y los limita a simples mandatos dirigidos a los poderes autonómicos (SSTC 247/2007 y 31/2010), cosa que también incluye el Estatuto andaluz. La disposición estatutaria se califica como un "derecho emergente" directamente reclamable por los particulares, acompañado de un mandato a los poderes públicos que les sitúa en la base de toda una serie de transformaciones que han de revisar los esquemas heteronormativos de nuestro modelo de sociedad ${ }^{28}$. Y también como un "derecho realmente novedoso", en la medida en que no se limita a reproducir o especificar el contenido de un derecho constitucional ni incorpora un derecho reconocido por la jurisprudencia constitucional ${ }^{29}$; ofreciendo una fórmula más amplia y comprensiva del fenómeno discriminatorio, al refundir la recepción constitucional de la igualdad formal (artículo $14 \mathrm{CE}$ ) y material (artículo 9.2 CE) en un solo precepto compresivo de ambas vertientes del principio de igualdad ${ }^{30}$.

Con todo, la ausencia de un reconocimiento estatutario como el que contiene Andalucía no ha impedido a las CCAA desplegar su capacidad legislativa para articular una regulación integral de la autodeterminación de género que supera en gran medida el enfoque antidiscriminatorio o igualitario por razón de género, haciendo uso de muy distintos títulos competenciales asumidos estatutariamente; aunque no cabe duda de las limitaciones al desarrollo autonómico que impone la competencia estatal reconocida en el artículo 149.1.8 ${ }^{\mathrm{a}} \mathrm{CE}$. Es por ello que, junto a los títulos de carácter general, fundamentalmente vinculados a la competencia estatutaria en materia de defensa y promoción del adecuado ejercicio de los derechos y deberes fundamentales de la ciudadanía, se invocan títulos competenciales más concretos como la protección y tutela de los menores, la promoción del empleo, los servicios sociales o la educación ${ }^{31}$, de

\footnotetext{
${ }^{28}$ Como un "derecho emergente" lo califica SALAZAR BENÍTEZ, O., "La identidad de género ...", pp. 75. Véase también SALAZAR BENÍTEZ, O., "El reconocimiento jurídico-constitucional de la diversidad afectiva y sexual", Revista de estudios políticos, 157, 2012, pp. 45-81.

29 Así lo sostiene BARRERO ORTEGA, A., Nuevos derechos y garantías, Tirant lo Blanch, Valencia, 2019 , p. 25, al acuñarlo como "un derecho realmente novedoso".

${ }^{30}$ En estos términos lo expresa GALERA VICTORIA, A., "La actividad legislativa en materia de igualdad efectiva entre mujeres y hombres", Investigación y género. Inseparables en el presente y en el futuro: IV Congreso Universitario Nacional "Investigación y Género". Sevilla, 21 y 22 de junio de 2012, VÁZQUEZ BERMÚDEZ, I. (Coord.), 2012, pp. 573, al señalar que el artículo 35 del Estatuto andaluz refunde en un solo precepto la recepción constitucional de la igualdad formal (artículo 14 CE) y material (artículo 9.2 $\mathrm{CE}$ ), amalgamando ambas vertientes del principio de igualdad junto a la previsión de nuevas categorías especialmente susceptibles de acciones discriminatorias como las "características genéticas" o la "orientación sexual".

${ }^{31}$ Algo similar ocurre en relación con la regulación autonómica en materia de igualdad de género, tal como apunta BALAGUER CALLEJÓN, F., "Derechos, principios y objetivos relacionados con la igualdad de género", Reformas estatutarias y Declaraciones de derechos, Instituto Andaluz de Administración Pública, BALAGUER CALLEJÓN, F. (Dir.), Sevilla, 2008, pp. 281 y sgtes., al señalar que la extensión e intensidad de las regulaciones estatutarias en materia de igualdad de género ha sido dispar ya que mientras algunos EEAA han optado por asumir la perspectiva de género con un significado y alcance decidido a hacer efectivo el mandato constitucional de promoción de la igualdad (Cataluña y Andalucía de modo singular), otros EEAA asumen la perspectiva de género en un sentido ciertamente limitado a su desarrollo y promoción (Comunidad Valenciana, Baleares, Aragón y Castilla y León).
} 
acuerdo con los cuales la posición prestacional de los poderes públicos autonómicos puede ofrecer una respuesta muy adecuada a las necesidades de las personas trans, sin que por ello dejemos de reconocer la necesidad de que el legislador estatal haga uso de los títulos competenciales que la $\mathrm{CE}$ le atribuye, y muy concretamente los vinculados a la legislación procesal $\left(149.1 .6^{\mathrm{a}} \mathrm{CE}\right)$, legislación civil $\left(149.1 .8^{\mathrm{a}} \mathrm{CE}\right)$ y bases en materia de sanidad (149.1.16 $\mathrm{CE})$.

Pioneras en aprobar una ley específica destinada a ofrecer una protección integral a las personas transexuales fueron la Ley Foral 12/2009, de 19 de noviembre, de no discriminación por motivos de identidad de género y de reconocimiento de los derechos de las personas transexuales ${ }^{32}$; y también la Ley vasca 14/2012, de 28 de junio, de no discriminación por motivos de identidad de género y de reconocimiento de los derechos de las personas transexuales No obstante, en ambos casos, una parte importante del articulado de estas leyes consiste en políticas de promoción o fomento, por lo que sus efectos legales están condicionados al efectivo desarrollo de políticas públicas que, en materia educativa, tienen un claro carácter programático llamado, entre otras cosas, a la formación de los profesionales o docentes que en mayor medida hayan de tratar con transexuales, o a sensibilizar al conjunto de la sociedad para evitar cualquier tipo de discriminación ${ }^{33}$.

Más tarde, otras CCAA han desplegado su capacidad legislativa en esta misma dirección, reconociendo derechos de las personas transexuales más allá de las medidas de prohibición de discriminación y de la sanción de conductas homofóbicas. Es el caso, entre otras, de la Ley canaria 8/2014, que reconoce a las personas que adoptan socialmente el sexo contrario al de su nacimiento el derecho de recibir de las Administraciones públicas canarias una atención integral y adecuada a sus necesidades médicas, psicológicas, jurídicas y de otra índole, en igualdad de condiciones con el resto de la ciudadanía y con independencia de la isla o municipio en que tengan su residencia. También la Ley aragonesa 4/2018, de 19 de abril, de identidad y expresión de género e igualdad social y no discriminación reconoce el derecho a la identidad de género libremente manifestada por referencia a que "toda persona tiene derecho a construir para sí una autodefinición con respecto a su cuerpo, sexo, identidad y expresión de género y su orientación sexual" (artículo 4). En similares términos se pronuncia la Ley madrileña 2/2016, de 29 de marzo, de Identidad y Expresión de Género e Igualdad Social y no Discriminación cuyo artículo 4 reconoce del derecho a la identidad de género libremente manifestado; y la Ley valenciana 8/2017, de 7 de abril, integral del reconocimiento del derecho a la identidad y a la expresión de género, cuyo artículo 1 reconoce el derecho de autodeterminación de

\footnotetext{
${ }^{32}$ La Ley Foral 12/2009 fue modifica en 2017 para adecuar su contenido a los Principios de Yogyakarta y reconducir el inicial enfoque patologizante. Así lo indica MALDONADO, J., "El reconocimiento del derecho a la identidad", p. 146, al señalar que la concepción anacrónica de Ley 3/2007, tanto por contradecir los Principios de Yogyakarta como por condicionar el reconocimiento de la identidad sexual a que la persona -quiera o no- someta a su cuerpo a modificaciones en los caracteres sexuales secundarios, se contagió a las primeras leyes sobre identidad sexual autonómicas (Navarra, seguida por la del País Vasco), lo que requirió la modificación en de la Ley Navarra de 2009.

${ }^{33}$ ELVIRA PERALES, A., “Transexualidad ...”, pp. 26-27.
} 
género a las personas que manifiesten una identidad de género sentida diferente a la asignada en el momento del nacimiento, y exige a los poderes públicos el respecto y la adopción de las medidas pertinentes para su garantía y tutela.

\section{3.- El reconocimiento del derecho de autodeterminación de género en la legislación valenciana}

En el marco de las competencias asumidas por el Estatuto de Autonomía de la Comunitat Valenciana, dos son las leyes de cabecera en relación con la autodeterminación de género $^{34}$. En primer lugar, la Ley 8/2017, de 7 de abril, integral del reconocimiento del derecho a la identidad y a la expresión de género, cuyo artículo 1 reconoce el derecho de autodeterminación de género a las personas que manifiesten una identidad de género sentida diferente a la asignada en el momento del nacimiento, y exige a los poderes públicos el respecto y la adopción de las medidas pertinentes para su garantía y tutela. Poco más tarde se aprueba la Ley 23/2018, de 29 de noviembre, de igualdad de las personas LGTBI, en la que desde un claro enfoque antidiscriminatorio se reconocen medidas que se proyectan sobre distintos ámbitos, en concreto en el ámbito educativo, con expresa referencia a la educación superior (artículo 25), a través de las cuales se desarrollarán políticas públicas para garantizar los derechos y la igualdad real y efectiva de las personas LGTBI.

El derecho de autodeterminación de género, tal como se ha configurado en la Ley 8/2017, de 7 de abril, integral del reconocimiento del derecho a la identidad y a la expresión de género en la Comunitat Valenciana tiene como sujetos a las personas que manifiesten una identidad de género sentida diferente a la asignada en el momento del nacimiento (artículo 1). No obstante, es un derecho muy limitado por la competencia estatal en materia de Derecho civil (artículo 149.1.8 ${ }^{\mathrm{a}} \mathrm{CE}$ ), de acuerdo con la cual sólo la rectificación registral del sexo, obtenida tras un diagnóstico de disforia de género y un tratamiento médico de al menos dos años, permitirá a la persona ejercer todos los derechos inherentes a su nueva condición. Es por ello que, pese al avance que puede suponer el reconocimiento del derecho subjetivo a la autodeterminación de género en la legislación valenciana - y muy concretamente en las posibilidades de adecuación de la documentación administrativa que ha surtir efectos en el ámbito prestacional de la Comunitat Valenciana- la trascendencia de la norma se ve seriamente limitada por la legislación estatal en la medida en que la identificación jurídica de las personas viene determinada por la inscripción en el Registro Civil, basada en el sexo biológico en el momento de la inscripción, que no

\footnotetext{
${ }^{34}$ El Estatuto de Autonomía de la Comunitat Valenciana no contempla el derecho de autodeterminación de género, como sí hace el Estatuto andaluz. No obstante, tal como indica el Preámbulo de la Ley 8/2017, la disposición legislativa encuentra anclaje en la competencia estatutaria referida a la defensa y promoción del adecuado ejercicio de los derechos y deberes fundamentales de su ciudadanía, así como las competencias en materia de organización administrativa y de los servicios públicos, en la protección y tutela de los menores, en la promoción del empleo, servicios sociales (artículo 49.1.24 ${ }^{\mathrm{a}}$ EA), la regulación, administración y gestión de la enseñanza (artículo 53 EA) y de las instituciones sanitarias públicas (artículo 54.1 EA), protección civil y seguridad pública. Todos estos títulos habilitan a la Comunitat Valenciana para realizar un planteamiento de atención integral en las diversas materias que afectan a la situación de las personas LGTBI.
} 
puede cambiarse hasta en tanto no se produzca la rectificación de la inscripción registral de acuerdo con la Ley estatal 3/2007.

Precisamente, la interpretación del alcance de la competencia que la Ley 8/2017 atribuye a la Generalitat valenciana en orden a la expedición de la documentación administrativa acorde con la identidad de género manifestada, suscitó ciertas dudas de constitucionalidad, resueltas a través del mecanismo de cooperación que supone la constitución de la Comisión Bilateral de Cooperación entre la Administración General del Estado y la Generalitat Valenciana. En concreto, respecto del artículo 9 de la Ley 8/2017, relativo a la documentación administrativa acorde a la identidad de género manifestada por la persona y que la Generalitat puede expedir para para el acceso a sus servicios administrativos y de toda índole, la Comisión Bilateral acordó interpretar el precepto en el sentido de que el reconocimiento autonómico como persona transexual se entiende a los efectos de la propia Ley y en el ámbito competencial de la Comunitat Valenciana, sin que afecte a la identidad jurídica del interesado en tanto no se produzca la rectificación de la inscripción registral regulada en la Ley estatal 3/2007, reguladora de la rectificación registral de la mención relativa al sexo de las personas ${ }^{35}$. De este modo se salva la presunta inconstitucionalidad del precepto, por invadir la competencia estatal reconocida en el artículo 149.1.8 ${ }^{\mathrm{a}} \mathrm{CE}$, en la medida en que la documentación autonómica que pudiera expedirse en modo alguno altera la identidad jurídica del interesado (que es materia de Derecho civil reservada al Estado de acuerdo con el artículo 149.1.8 ${ }^{\mathrm{a}} \mathrm{CE}$ ), en tanto no se produzca la rectificación de la inscripción registral de acuerdo con la Ley estatal 3/2007, de 15 de marzo, reguladora de la rectificación registral de la mención relativa al sexo de las persona.

En cuanto al contenido material del derecho de autodeterminación de género, la Ley 8/2017 sigue el criterio de la Agencia de Derechos Fundamentales de la Unión Europea en su definición de identidad de género y expresión de género, por referencia a una identidad de carácter emocional, a la vivencia interna e individual del género tal y como cada persona la siente profundamente, incluyendo la vivencia personal del cuerpo ${ }^{36}$, pero

\footnotetext{
${ }^{35}$ Véase la Resolución de 23 de enero de 2018, de la Directora General de Relaciones con la Unión Europea y el Estado, por la que se publica el Acuerdo de la Comisión Bilateral de Cooperación Administración General del Estado-Generalitat en relación con la Ley 8/2017, de 7 abril, de la Generalitat, integral del reconocimiento del derecho a la identidad y a la expresión de género en la Comunitat Valenciana (DOGV de 25 de enero). Dicha resolución pone fin a las discrepancias formuladas a ciertos preceptos de la Ley. En concreto, respecto del artículo 9, relativo a la documentación que puede expedir al Generalitat para hacer efectivo el derecho de autodeterminación, ambas partes coinciden en interpretar el precepto en el sentido de que el reconocimiento como persona transexual se entiende a los efectos de la propia ley y en el ámbito competencial de la Comunitat Valenciana, sin que afecte a la identidad jurídica del interesado en tanto no se produzca la rectificación de la inscripción registral regulada en la Ley 3/2007, de 15 de marzo, reguladora de la rectificación registral de la mención relativa al sexo de las personas.

${ }^{36}$ De acuerdo con el Preámbulo de la Ley 8/2017, la identidad de género está generalmente acompañada del deseo de vivir y recibir aceptación como miembro de dicho género e incluso del deseo irrenunciable de modificar, mediante métodos hormonales, quirúrgicos o de otra índole, el propio cuerpo para hacerlo lo más congruente posible con el género sentido como propio cuando no se corresponde con el asignado al nacer. En esta dirección, véase la posición de BELDA PÉREZ-PEDRERO, E., "Transexualidad y Derechos Fundamentales...", p. 134, referida al componente emocional de la identidad reconocida en los documentos públicos. También en la Introducción a los Principios de Yogyakarta, tras reconocer que la orientación
} 
también otras como la vestimenta o como el modo de hablar y de expresarse, que son manifestaciones externas y públicas de las personas y que también el Derecho ha de amparar. Precisamente esta dimensión pública es la que llevó al Senado norteamericano a la derogación de la ley conocida como Don't ask, don't tell (no preguntes, no lo cuentes), que prohibía a los gays y lesbianas servir de forma abierta en el ejército norteamericano ${ }^{37}$, vinculando el derecho de autodeterminación a la dignidad del individuo. En este sentido, la identidad de género es algo más que una cuestión privada, repercute en la dimensión pública de las personas y reclama una atención garantista por parte del Derecho ${ }^{38}$. Se formula así un derecho de autodeterminación o de libre elección de género que en cierto modo rompe el papel del Estado en la asignación binaria del género hombre/mujer efectuada en el momento del nacimiento, y que guarda una estrecha relación con el concepto de "autonomía relacional", que es aquella que "nos permite rebelarnos contra la adscripción estática y coercitiva, heterónoma, a relaciones concretas, y contra el protagonismo que éstas puedan asumir en la definición de nuestra personalidad a costa de nuestra capacidad de auto-normarnos" $" 39$. En la base de la definición se advierte una clara superación del enfoque discriminatorio en favor del desarrollo de la afectividad y la sexualidad con plena libertad, lo que ha de incluir un adecuado tratamiento del componente de publicidad o exteriorización (libertad de vestimenta, modo de hablar y modales).

En línea con este concepto amplio de autodeterminación de género sentido o vivido por cada persona, el artículo 5 de la Ley 8/2017 identifica un haz de manifestaciones o facultades a través de las cuales se expresa este derecho subjetivo, sin perjuicio de los regímenes específicos más favorables ${ }^{40}$, y que como tal concede a las personas las siguientes facultades:

sexual y la identidad de género son esenciales para la dignidad y la humanidad de toda persona y no deben ser motivo de discriminación o abuso, se señala que "La identidad de género se refiere a la vivencia interna e individual del género tal como cada persona la siente profundamente, la cual podría corresponder o no con el sexo asignado al momento del nacimiento, incluyendo la vivencia personal del cuerpo (que podría involucrar la modificación de la apariencia o la función corporal a través de medios médicos, quirúrgicos o de otra índole, siempre que la misma sea libremente escogida) y otras expresiones de género, incluyendo la vestimenta, el modo de hablar y los modales".

${ }^{37}$ Sobre esta cuestión, SALAZAR BENÍTEZ, O., "El reconocimiento jurídico-constitucional...”, pp. 4647.

${ }^{38}$ En relación con el libre desarrollo de la afectividad y la sexualidad, SALAZAR BENÍTEZ, O., "El reconocimiento jurídico-constitucional ...”, p. 47, señala que es necesario reconducirlas a las garantías derivadas del principio de igualdad y profundizar en el concepto jurídico-constitucional de identidad para conseguir un marco en el que cada individuo no sólo no sufra discriminación alguna por sus opciones personales sino que, al contrario, las desarrolle con plena libertad.

${ }^{39}$ Así lo expresa SALAZAR BENÍTEZ, O., "El derecho a la identidad sexual de las personas menores de edad. Comentario a la STC 99/2019, de 18 de julio de 2019", Revista de Derecho Constitucional Europeo, 32, 2019.

40 Téngase en cuenta que la redacción del artículo 5 del Anteproyecto de ley integral del reconocimiento del derecho a la identidad y a la expresión de género en la Comunidad Valenciana se disponía que "las disposiciones de esta Ley se entienden sin perjuicio de los regímenes específicos más favorables establecidos en los reglamentos comunitarios, estatales o regionales debido a las diferentes causas de discriminación previstas en la ley". El Consell Jurídic Consultiu de la Comunitat Valenciana, en el preceptivo Dictamen a dicho Anteproyecto (Dictamen no 2016/0494, de 6 de octubre de 2016. Expediente 0526/2016), señaló que el último inciso de esta frase resultaba ininteligible y, en todo caso, restrictivo de 
a) el derecho al reconocimiento de su identidad de género libremente manifestada, sin la necesidad de prueba psicológica o médica;

b) el derecho al libre desarrollo de la personalidad acorde a su identidad y expresión de género;

c) el derecho a ser tratadas de conformidad a su identidad de género en todos los ámbitos públicos y privados;

d) el derecho a que se respete y proteja su integridad física y psíquica, así como sus decisiones en relación a su identidad y expresión de género;

e) el derecho a recibir de la Generalitat una atención integral y adecuada a sus necesidades médicas, psicológicas, jurídicas, educativas, sociales, laborales y culturales en referencia al desarrollo de su identidad y expresión de género; y

f) el derecho a que se proteja el ejercicio efectivo de su libertad y a no sufrir discriminación por motivo de identidad o expresión de género en todos los ámbitos de la vida.

Estamos ante un precepto autonómico muy avanzado en relación con el reconocimiento de un verdadero derecho subjetivo en favor de las personas LGTBI $^{41}$, conformado por un conjunto de manifestaciones que explicitan un grado de libertad máxima de la persona en la expresión de la identidad de género sentida (en concreto, las letras a, b, c y d del artículo 5). En el ámbito autonómico sobre el que se proyecta la Ley, ampara una amplia capacidad individual para determinar la identidad de género, sin necesidad de prueba psicológica o médica y por tanto de la intervención de un tercero, en sintonía con el enfoque despatologizante que proclaman los textos internacionales, y que algunos países han implementado sin ambages ${ }^{42}$.

Para la satisfacción de este derecho, la Ley impone a las Administraciones Públicas de la Comunitat Valenciana una serie de obligaciones que claramente van más allá de la tutela antidiscriminatoria, en correspondencia con el carácter de derecho social que ostenta la autodeterminación de género y con la naturaleza prestacional de este tipo de derechos que, a diferencia de los derechos civiles y políticos que son autoejecutivos e inmediatamente eficaces, necesitan para su delimitación además de la contribución del

la afirmación contenida en el primer inciso, por lo que proponía la supresión o, en su caso, la aclaración de su significado. El actual artículo 5 de la ley ha omitido dicho inciso, y mantiene la salvaguarda de aplicación de regímenes específicos establecidos en la normativa comunitaria, estatal o autonómica, que resulten más favorables que la ley valenciana.

${ }^{41}$ En relación con el concepto de "derecho subjetivo" frente al "interés legítimo" en términos de protección judicial plena, véase MEDINA ALCOZ, L., "Historia del concepto de derecho subjetivo en el Derecho Administrativo español”, Revista de Derecho Público: Teoría y Método, Vol. 1, 2021, pp. 7-52.

${ }^{42}$ En relación con la despatologización y la autodeterminación implementada en distintos países del continente americano, diferenciando entre los que sólo requieren de un procedimiento administrativo y aquellos otros que exigen la intervención jurisdiccional, véase RUBIO MARÍN, R. y OSELLA, S., "El nuevo derecho constitucional a la identidad de género entre la libertad de elección, el incremento de categorías y la subjetividad y fluidez de sus contenidos. Un análisis desde el Derecho comparado", Revista Española de Derecho Constitucional, 118, 2020, pp. 45-75. 
legislador, una actividad prestacional ulterior de la Administración. Son por ello derechos dependientes de la intervención de la Administración, que han evolucionado en sintonía con las transformaciones que exige el modelo de Estado regulador y garante ${ }^{43}$. Por tanto, se impone a la Administración una amplia actividad prestacional que se proyecta sobre muy distintos ámbitos (educativo, sanitario, social, laboral, familiar, deportivo...) ${ }^{44}$ y requiere de muy distintas y variadas acciones para garantizar una tutela integral, en gran medida encaminadas a la remoción de obstáculos para la efectiva realización del derecho, aunque no $\mathrm{sólo}^{45}$. Nuestro interés se detiene únicamente en las acciones que la Administración debe adoptar en materia educativa, a la que dedicamos el apartado siguiente.

\section{II.- LA TUTELA DE LA AUTODETERMINACIÓN DE GÉNERO A TRAVÉS DE LA INTERVENCIÓN EN MATERIA EDUCATIVA}

\section{1.- Los mecanismos de la legislación autonómica para la tutela integral}

Nuestro interés en el análisis que mostramos se centra en la proyección del derecho de autodeterminación en el ámbito educativo, para lo cual partimos del marco normativo contenido en la legislación valenciana, dadas las amplias posibilidades que ofrece, sin perjuicio de las oportunas referencias a otras disposiciones. En efecto, la Ley 8/2017 -y también la Ley $23 / 2018$, en términos similares ${ }^{46}$ - dispone un conjunto de previsiones relativas a las actuaciones que en el ámbito educativo ha de desarrollar la Generalitat Valenciana en materia de identidad de género, expresión de género y diversidad sexual (artículo 21). Muy concretamente, para la tutela integral en el ámbito educativo, la Ley se refiere a la aprobación por parte de la Generalitat de un protocolo de atención educativa

\footnotetext{
${ }^{43}$ Como señala MUÑOZ MACHADO, S., Tratado de Derecho administrativo y Derecho Público General. Tomo XIV. La actividad regulatoria de la Administración, Editorial BOE, 2015, p. 183 y pp. 192-193, respecto de la posición de la Ley en el cumplimiento del encargo constitucional de concretar las facultades, deberes y obligaciones que comprende cada uno de los derechos consagrados en la Constitución, las operaciones de delimitación, esto es, de fijación del contenido ordinario de cada derecho, no concluyen en la regulación legal, sino que se completan a través de actuaciones de la propia Administración que usa, a tal efecto, las potestades de que ordinariamente dispone, principalmente de carácter normativo o ejecutivo, es decir, a través de reglamentos y actos. En relación con la administrativización de las garantías de los derechos fundamentales y la función de regulación que en ello asume la Administración, véanse las pp. $258-260$.

${ }^{44}$ Un análisis de los principales problemas que afronta el colectivo LGTBI en el ámbito de la Administración militar, en el ámbito tributario, de atención sanitaria, prestaciones sociales, extranjería y derecho de asilo pueden consultarse en DÍAZ CREGO, M., "Administraciones Públicas españolas y Derechos del colectivo LGTBI", Revista General de Derecho Constitucional, 17, 2013.

${ }^{45}$ Sobre la función de la norma también es el fundamento de la actividad prestacional de la Administración, LAGUNA DE PAZ, J. C., "Regulación, externalización de actividades administrativas y autorregulación", Revista de Administración Pública, 185, 2011, p. 93.

${ }^{46}$ Véase el Capítulo 3 de la Ley 23/2018, de 29 de noviembre, de igualdad de las personas LGTBI, relativo a las "Medidas en el ámbito de la educación", por referencia a las actuaciones en materia de diversidad sexual, familiar y de género (artículo 21), a las acciones de prevención, acompañamiento e intervención (artículo 22), a las acciones de formación, participación y divulgación (artículo 23), a las actuaciones específicas en los centros educativos (artículo 24) y a las actuaciones en el ámbito universitario (artículo 25).
} 
a la identidad de género que respete la identidad sentida de las personas LGTBI en los centros educativos (artículo 22), así como a la adopción de medidas para incorporar contenidos educativos sobre la identidad y expresión de género, la diversidad sexual en los diferentes ciclos formativos (artículo 23) y la promoción de acciones de formación y divulgación dirigidas a la comunidad educativa no universitaria (artículo 24). Junto a estas previsiones generales en materia educativa, dirigidas fundamentalmente a fijar la posición que debe asumir la Generalitat para hacer efectivo el reconocido derecho de autodeterminación de género, el artículo 25 contiene ciertas disposiciones dirigidas concretamente a las Universidades de la Comunitat Valenciana, con el alcance que más adelante señalamos.

Así pues, la elaboración de un protocolo de atención educativa a la identidad de género por parte de la Generalitat (1.1), la adopción de concretas medidas de ordenación académica (1.2) y la formación de la comunidad educativa no universitaria (1.3) son los tres pilares sobre los que se asienta la intervención educativa para la efectividad del derecho de autodeterminación de género.

\section{1.- La elaboración de un protocolo de atención educativa a la identidad de género}

El artículo 22 de la Ley 8/2017 encomienda a la Generalitat la elaboración de un protocolo de atención educativa a la identidad de género, que pondrá al alcance de los centros educativos y que las Universidades deberán adaptar. Dicho protocolo tiene por objetivo garantizar el pleno ejercicio del derecho de autodeterminación de género en el ámbito educativo, y para ello la Ley establece que deberá contener las siguientes determinaciones:

a) El respeto a las identidades o expresiones de género que se den en el ámbito educativo y el libre desarrollo de la personalidad del alumnado de acuerdo con su identidad. Para ello, el citado protocolo y sin perjuicio de que en las bases de datos de la administración educativa se mantengan los datos de identidad registrales, establecerá la adecuación de la documentación administrativa de exposición pública y la que pueda dirigirse al alumnado y sus familias, haciendo figurar el nombre escogido por la persona matriculada, con el consentimiento de sus representantes legales, en los casos que lo requieran. En el supuesto de que la persona matriculada no se encuentre en situación de emancipación o no cuente con la suficiente condición de madurez, el nombre será indicado por sus representantes legales, evitando que aparezca en tipografía diferente al del resto del alumnado.

b) El respeto a la intimidad del alumnado.

c) La coordinación entre las áreas de educación, sanidad y servicios sociales, con el objetivo de garantizar una rápida detección y actuación ante situaciones discriminatorias o que atenten contra la identidad de género expresada por la o el menor.

d) Que la comunidad educativa del centro se dirija a las personas trans por el nombre que hayan elegido. 
e) El respeto a la imagen física, así como la libre elección de su indumentaria según la identidad de género sentida.

f) El acceso y el uso de las instalaciones del centro de acuerdo con la identidad de género sentida, incluyendo los lavabos y los vestuarios.

Como podrá advertirse, el contenido del protocolo educativo respeta la competencia estatal relativa al cambio registral de sexo expresada en la Ley 3/2007, aunque impulsa el tratamiento de las personas trans de acuerdo con la identidad sentida, facilitando la adecuación de la documentación administrativa del alumnado para que figure el nombre escogido y así se les pueda identificar en todos los ámbitos educativos. Sin duda, éste es uno de los aspectos con mayor desarrollo normativo, tanto a nivel escolar como universitario. No obstante, el precepto recoge otras facetas, como son el respeto a la intimidad, a la imagen física y la garantía de la libre elección de su indumentaria según la identidad de género sentida, que también han de abordarse a través del protocolo, por ser expresión del componente de publicidad o exteriorización de la identidad de género sentida por el alumnado que, como se ha dicho, forma parte del derecho de autodeterminación. También el protocolo ha de señalar los mecanismos de coordinación, tanto entre las distintas áreas educativas, muy concretamente las que permeabilizan la transición entre las distintas etapas educativas, así como con las áreas de sanidad y servicios sociales, que se atienden desde fuera del sistema educativo.

Hasta la fecha, la Generalitat Valenciana no ha aprobado un protocolo en el que se desarrollen las previsiones del citado artículo 22 de la Ley 8/2017, de acuerdo con las cuales los centros educativos deberán implementar sus correspondientes documentos docentes y, las Universidades proceder a su adaptación. No obstante, mucho antes de la vigencia de la Ley 8/2017, el Consell había aprobado el Decreto 39/2008, sobre la convivencia en los centros docentes no universitarios sostenidos con fondos públicos y sobre los derechos y deberes del alumnado, padres, madres, tutores o tutoras, profesorado y personal de administración y servicios. Esta disposición reglamentaria recogía entre los principios generales que deben regir para asegurar la convivencia en los centros educativos, el de igualdad de todo el alumnado en derechos y deberes, sin más distinciones que aquellas que se derivan de su edad y de las etapas o los niveles de las enseñanzas que cursan (artículo 3), por lo que daba soporte a los centros educativos para la implementación de acciones encaminadas a la tutela de la autodeterminación de género $^{47}$. En aplicación de este precepto reglamentario y de la posterior Orden 62/2014, por la que se actualiza la normativa que regula la elaboración de los planes de convivencia en los centros educativos de la Comunidad Valenciana y el establecimiento de los protocolos de actuación e intervención ante supuestos de violencia escolar ${ }^{48}$, se publica

\footnotetext{
${ }^{47}$ Decreto 39/2008, de 4 de abril, del Consell, sobre la convivencia en los centros docentes no universitarios sostenidos con fondos públicos y sobre los derechos y deberes del alumnado, padres, madres, tutores o tutoras, profesorado y personal de administración y servicios (DOGV de 9 de abril).

${ }^{48}$ Orden 62/2014, de 28 de julio, de la Conselleria de Educación, Cultura y Deporte, por la que se actualiza la normativa que regula la elaboración de los planes de convivencia en los centros educativos de la
} 
la Instrucción de 15 de diciembre de 2016, por la que se establece el protocolo de acompañamiento para garantizar el derecho a la identidad de género, la expresión de género y la intersexualidad ${ }^{49}$. Dicha Instrucción comprende orientaciones y pautas de intervención para la adecuada atención al alumnado que expresa una identidad de género divergente con respecto al estereotipo de sexualidad binaria y a los alumnos con una anatomía sexual y reproductiva no binaria o intersexual. De este modo se asegura que el alumnado inmerso en un proceso de transición de género o que exprese un género divergente o anatomía sexual intersexual no quede excluido del sistema o no reciba el tratamiento integrador e igualitario que la escuela debe garantizar. Tal como indica la citada Instrucción, en los casos en que se detecte un posible caso de intersexualidad, identidad o expresión de género divergente, el centro docente o la familia del menor activará la aplicación de estas reglas procedimentales, al objeto de acompañar al alumno/a en el proceso de construcción personal y conseguir la plena inclusión social ${ }^{50}$. Estamos, pues, ante una disposición que participa de la naturaleza jurídica propia de las instrucciones u órdenes de servicio, y por tanto con efectos ad intra, a través de la cual la Administración educativa da indicaciones a los centros escolares para el acogimiento integral de la diversidad en todos los ámbitos ${ }^{51}$-y no sólo como un complemento de los planes de convivencia impulsados por la Ley Orgánica 2/2006, de Educación ${ }^{52}$ - así como un esquema del procedimiento a seguir en el que se incluya la coordinación entre los distintos órganos intervinientes ${ }^{53}$.

Comunidad Valenciana y el establecimiento de los protocolos de actuación e intervención ante supuestos de violencia escolar (DOGV de 1 de agosto).

49 Instrucción del 15 de diciembre de 2016, del Director General de Política Educativa, por la que se establece el protocolo de acompañamiento para garantizar el derecho a la identidad de género, la expresión de género y la intersexualidad (DOGV de 27 de diciembre).

${ }^{50}$ La citada Instrucción de 15 de diciembre de 2016 incorpora un guía en la que se procedimentaliza la actuación a seguir por parte de los centros educativos, identificando a su vez cuáles son los órganos que intervienen en cada una de las fases y cómo se relacionan entre ellos, así como las medidas organizativas y de carácter educativo que deban adoptarse y el seguimiento y control de las mismas.

${ }^{51}$ Por ello, tal como señala la Instrucción de 15 de diciembre de 2016, la diversidad y la interrelación que genera el contexto educativo debe quedar recogida de forma global en el Proyecto educativo de centro y concretarse en las programaciones didácticas, en el Plan de acción tutorial, en el Plan de convivencia e igualdad, en la Programación de actividades extraescolares y complementarias y en los reglamentos de régimen interno.

52 Tal como establece el artículo 121.2 de la Ley Orgánica 2/2006, de Educación, los planes de convivencia deben integrarse en los proyectos educativos de los centros públicos o privados y recogerán, al menos, la forma de atención a la diversidad del alumnado, las medidas relativas a la acción tutorial y los planes de convivencia y de lectura. Deberán respetar los principios de no discriminación y de inclusión educativa como valores fundamentales. La mayoría de CCAA ha desarrollado la implantación de los planes de convivencia. A tal efecto, véase el Decreto 114/2011, de 11 de mayo, por el que se regula la convivencia en el ámbito educativo de la Comunidad Autónoma de Canarias, el Decreto 16/2016, de 9 de marzo, por el que se establecen las normas de convivencia en los centros docentes no universitarios sostenidos con fondos públicos de la Comunidad Autónoma de la Región de Murcia o el Decreto 32/2019, de 9 de abril, por el que se establece el marco regulador convivencia en los centros docentes de la Comunidad de Madrid.

${ }^{53}$ En concreto, contempla la coordinación con la Unidad de referencia para la Identidad de Género y la Intersexualidad (UIGI), al objeto de obtener el asesoramiento de los profesionales de la Unidad para ajustar la respuesta educativa a las necesidades del alumnado con identidad de género divergente o con desarrollo sexual diferente. 
Sin desmerecer la importancia que han tenido los planes de convivencia en los centros educativos y el soporte que esta Instrucción de la Dirección General de Política Educativa supone para la prevención de situaciones de malestar, discriminación, acoso o trato desigual del alumnado trans e intersexual ${ }^{54}$, lo cierto es que con ello no se da total cumplimiento a las exigencias del artículo 22 de la Ley 8/2017, que concibe la elaboración del protocolo de atención educativa a la identidad de género como piedra angular de la intervención administrativa para la garantía del derecho de autodeterminación en el campo educativo. En este sentido, el protocolo ha superado la inicial función de prevención de riesgos y regulación de la convivencia, propio de los documentos soft law y en concreto de los planes de convivencia, para convertirse en una herramienta encaminada a garantizar la tutela integral del colectivo trans en los centros educativos de la Comunitat Valenciana ${ }^{55}$. Tal es su trascendencia para la efectividad del derecho de autodeterminación de género en el ámbito escolar que la Ley lo impone a todos los centros sostenidos con fondos públicos; previsión normativa que se ha visto confirmada tras la desestimación del recurso contencioso-administrativo formulado contra el artículo 29 del Decreto 102/2018, integral del reconocimiento del derecho a la identidad y a la expresión de género, de acuerdo con el cual se establece su obligado cumplimiento para los centros docentes públicos y concertados ${ }^{56}$.

En efecto, la Sentencia del TSJCV n ${ }^{\circ}$ 200/2019, de 15 de mayo, ha confirmado el precepto reglamentario aprobado en desarrollo de la Ley 8/2017, señalando que el cumplimiento obligatorio del Protocolo de atención educativa a la identidad de género, tanto en los centros públicos como en los centros privados concertados, no es contrario a los artículos 14 y 27.6 CE; o lo que es lo mismo, que la exigencia de este Protocolo a todos los centros sostenidos por la Administración pública no supone discriminación irracional e

\footnotetext{
${ }^{54}$ De acuerdo con la citada Orden 62/2014, entre las medidas que deben contener los Planes de Convivencia se encuentran las acciones que fomenten el respeto a la diversidad y la igualdad entre hombres y mujeres, a través de la educación de los sentimientos y de las emociones, así como la capacidad de elección, basada en argumentos de validez y en coherencia con los valores de libertad, respeto, igualdad y solidaridad (artículo 8, letra f). Véanse los Anexos contenidos en la citada Orden por referencia a los Procedimientos de intervención ante supuestos de violencia escolar, que se concretan en el acoso escolar y ciberacoso (Anexo I), Conductas que alteran la convivencia de forma grave y reincidente: insultos, amenazas, agresiones, peleas y/o vandalismo (Anexo II), Maltrato infantil (Anexo III), Violencia de género (Anexo IV), Agresiones hacia el profesorado y/o personal de administración y servicios (Anexo V). Por último, se anexan unas Consideraciones específicas, ante cualquiera de las situaciones planteadas en los anexos, si se producen fuera del centro (Anexo VI).

${ }_{55}$ En relación con el Protocolo de acoso elaborado por las Universidades, señala ALMODOVAR IÑESTA, M., "Algunas cuestiones técnico jurídicas ...", p. 32, que "los protocolos se constituyen en una herramienta realmente eficaz no solo en el ámbito laboral sino también en el entorno académico, cultural, deportivo y/o de servicios de cada Universidad, amparando situaciones muy diversas, acoso entre pares, entre profesor/alumno, entre alumno/profesor, alumno/PAS, PAS/alumno, becario/alumno, alumno/becario, etc".

${ }^{56}$ El artículo 29 del Decreto 102/2018, de 27 de julio, del Consell, de desarrollo de la Ley 8/2017, integral del reconocimiento del derecho a la identidad y a la expresión de género en la Comunitat Valenciana (DOGV de 31 de agosto) establece que el Protocolo de atención educativa a la identidad de género es de obligado cumplimiento para todos los centros sostenidos con fondos públicos, si bien los centros privados no sostenidos con fondos públicos se regirán por sus propias normativas, aunque tendrán que cumplir las garantías descritas en el artículo 22 de la Ley 8/2017, y en caso de no disponer de normativa propia se regirán por el protocolo elaborado por la Generalitat.
} 
injustificada con respecto al resto de centros privados no sostenidos con fondos públicos, ni tampoco vulnera su ideario o carácter propio $^{57}$. El debate sobre esta cuestión ya se había suscitado en la tramitación de la disposición reglamentaria impugnada, con un voto particular emitido en el preceptivo informe del Consell Jurídic Consultiu ${ }^{58}$, no secundado por la mayoría del órgano consultivo ni tampoco por los informes de la Abogacía de la Generalitat $^{59}$. La discusión jurídica ha quedado zanjada tras la citada decisión judicial, reconociéndose explícitamente el valor que supone el sostenimiento de los centros educativos con fondos públicos - pieza clave del servicio público de la educación- a los efectos de la obligatoriedad de las disposiciones a través de las cuales se expresan las

\footnotetext{
57 Véase la Sentencia del TSJCV no 200/2019, de 15 de mayo (rec. 371/2018), en relación con el recurso presentado por Feceval, FCAPA y FERE-CECA COVAL contra el artículo 29 del Decreto 102/2018, que desarrolla la Ley 8/2017 en orden a si la imposición obligatoria del protocolo de atención educativa a la identidad de género que apruebe la Conselleria competente en materia educativa cercena su libertad de creación de centros docentes y, en particular, su derecho al propio ideario educativo. La Sentencia rechaza el recurso señalando que: "el precepto reglamentario cuando impone el citado protocolo no restringe el ámbito de dicho derecho constitucional de los centros religiosos concertados, pues, dicho ámbito (al igual que todas las manifestaciones del genérico derecho a la educación recogido sintéticamente en el apartado 1 del artículo $27 \mathrm{CE}$ ) tienen límites y, uno de ellos, es precisamente, el respeto a los principios constitucionales y los derechos y libertades fundamentales, de suerte que lo afectado, en su caso, por la imposición obligatoria del protocolo de identidad de género sería un ámbito o contenido de ese ideario sin cobertura constitucional, pues, no existe un derecho potencial de estos centros (y de ningún otro) a ostentar un ideario propio contrario al derecho de igualdad o, si se quiere, ideario propio en el que se recogiese un modelo educativo que contuviera pautas educativas que "no se respetase las identidades o expresiones de género que se den en el ámbito educativo y el libre desarrollo de la personalidad del alumnado de acuerdo con su identidad" así como las restantes "garantías" que la Ley en su artículo 22 ha positivizado, motivo por el que, probablemente, no se ha solicitado la elevación de la cuestión de inconstitucionalidad del indicado precepto. Por tanto, de conformidad con el artículo 5.1 de la LOPJ en relación con el artículo 27.6 $\mathrm{CE}$, el precepto reglamentario impugnado no invade el derecho a la libertad de creación. Igualmente, estimamos, con el mismo razonamiento que tampoco restringe el derecho de los centros a ostentar un protocolo de identidad de género distinto al que se le impone y, además, acorde con su propio ideario. Esto es, el precepto reglamentario no impide que los centros elaboren, a mayor abundamiento, "otros" protocolos de identidad de género, ni tampoco otros protocolos acordes con su ideario, pues, como se ha dicho ese derecho constitucional de elaborar y desarrollar su ideario educativo no tiene la extensión pretendida. Como dice la doctrina constitucional anteriormente citada: "En este sentido, resulta claro que el carácter propio o ideario no sería aceptable si tiene un contenido incompatible por sí mismo con los derechos fundamentales o si, sin vulnerarlos frontalmente, incumple la obligación, derivada del artículo 27.2 de la Constitución, de que la educación prestada en el centro tenga por objeto el pleno desarrollo de la personalidad humana en el respeto a los principios democráticos de convivencia, y a los derechos y libertades fundamentales en su concreta plasmación constitucional, pues estos han de inspirar cualquier modelo educativo, público o privado".

${ }_{58}$ Véase el voto particular emitido en el preceptivo Dictamen del Consell Jurídic Consultiu (Dictamen $\mathrm{n}^{\circ}$ 503/2018. Expediente 380/2018) en relación con el art. 30 del Proyecto de Decreto de desarrollo de la Ley $8 / 2017$, integral del reconocimiento del derecho a la identidad y a la expresión de género en la Comunitat Valenciana, relativo al "Protocolo de atención educativa a la identidad de género" (actual artículo 29 del Decreto 102/2018), en relación con la obligatoriedad de dicho protocolo en todos los centros sostenidos con fondos públicos, incluyendo entre ellos los centros privados concertados. En opinión del Consejero discrepante (Ilmo. Sr. Fliquete Lliso), la aplicación obligatoria del "Protocolo de atención educativa a la identidad de género" vulnera el derecho de los centros privados que disponen de financiación pública a establecer su carácter propio. También es contrario al principio de reserva de ley orgánica artículo 81.1 CE e invade las competencias exclusivas del Estado del artículo 149.1 CE.

${ }^{59}$ Estos informes pueden consultarse desde la dirección electrónica: http://inclusio.gva.es/va/expedientsnormativa-tramitada/-/asset_publisher/QayBz1vLUQvl/content/ley-8-2017-de-7-de-abril-de-lageneralitat-integral-del-reconocimiento-del-derecho-a-la-identidad-y-a-la-expresion-de-genero-en-lacomunitat-valenciana (último acceso, diciembre de 2020).
} 
políticas públicas en materia de identidad de género, aunque no sean compartidas por todos en todos los casos. Ciertamente, aunque muchas de estas políticas han sido objeto de múltiples impugnaciones durante los últimos años, fundamentalmente en materia lingüística, los centros educativos concertados han aceptado la implantación de los protocolos de convivencia escolar, que son de obligado cumplimiento para todos los centros educativos sostenidos con fondos públicos ${ }^{60}$, sin mostrar reticencias, al menos explicitadas jurídicamente. Por el contrario, la obligatoriedad de protocolos de identidad de género ha suscitado mucho rechazo en ciertos centros y aunque, como se ha dicho, finalmente se ha impuesto por decisión judicial, no deja de evidenciar el poso cultural que las cuestiones vinculadas con la identidad de género todavía producen en gran parte de la sociedad.

\section{2.- La adopción de medidas de ordenación académica}

Además de la elaboración de un protocolo de atención educativa, la efectividad del derecho de autodeterminación requiere la adopción de medidas de ordenación académica por parte de la Generalitat, referidas a la incorporación de contenidos educativos sobre la identidad y expresión de género (artículo 23 Ley 8/2017). Esta previsión no sólo se proyecta respecto de las asignaturas y sus currículos, sino de manera transversal para todas las actividades que se desarrollen en los centros educativos. A estas posibilidades curriculares contenidas en la legislación educativa se han de añadir otras exigencias formativas dirigidas a toda la comunidad educativa, entre las cuales se encuentran las que impone la Ley $2 / 2010$, de 3 de marzo, de salud sexual y reproductiva y de la interrupción voluntaria del embarazo respecto de la formación en salud sexual y reproductiva, en relación con la salud sexual y reproductiva, que deben integrarse en el currículo educativo de manera adecuada a la edad ${ }^{61}$.

En relación con los currículos académicos, como sabemos, las CCAA ostentan competencias de desarrollo de la legislación estatal básica (artículo 149.1.30 CE) y pueden fijar hasta el 50\% de los de los horarios escolares cuando exista lengua cooficial (artículo $6 \mathrm{LOE})^{62}$. En el caso de la Comunitat Valenciana, dentro de esta horquilla lectiva y como complemento al currículo básico de cada una de las etapas y niveles escolares, la

\footnotetext{
${ }^{60}$ En la Comunitat Valenciana, la implantación de planes de convivencia en los centros educativos se impone a todos los centros sostenidos con fondos públicos. El Decreto 39/2008, de 4 de abril, del Consell, sobre la convivencia en los centros docentes no universitarios sostenidos con fondos públicos y sobre los derechos y deberes del alumnado, padres, madres, tutores o tutoras, profesorado y personal de administración y servicios dispone que el proyecto educativo del centro recogerá los valores, los objetivos y las prioridades de actuación, así como el tratamiento transversal en las áreas, materias o módulos de la educación en valores y otras enseñanzas, y asigna a la dirección de los centros públicos y a los titulares de los centros privados concertados la garantía y responsabilidad en la aplicación de las normas de convivencia incluidas en dicho proyecto (artículo 8).

${ }^{61}$ La Ley $2 / 2010$, de 3 de marzo, de salud sexual y reproductiva y de la interrupción voluntaria del embarazo establece la obligatoriedad de incorporar en el sistema educativo la formación en salud sexual y reproductiva, de manera adecuada a la edad (artículo 9), así como el apoyo de los poderes públicos a la realización de actividades formativas dirigidas a toda la comunidad educativa (artículo 10).

${ }^{62}$ Recuérdese que de acuerdo con la STC 14/2018, los aspectos básicos del currículo comprenden la fijación de objetivos por bloques temáticos en relación a cada disciplina, materia o asignatura, así como los horarios mínimos que se consideren necesarios para su enseñanza efectiva y completa.
} 
Generalitat debe establecer contenidos curriculares en materia de identidad de género, que los centros docentes han de complementar a través de los documentos académicos del centro, como manifestación de la autonomía pedagógica que ampara el principio de descentralización en las etapas educativas no universitarias (artículo 120 LOE) ${ }^{63}$. En esta dirección se había expresado el Plan Director de Coeducación presentado por la Generalitat en marzo de 2018, diseñado como documento de trabajo para el desarrollo de las políticas públicas en materia de coeducación. Este instrumento estratégico de Derecho blando contiene entre sus directrices el impulso de medidas tendentes a garantizar el respeto efectivo de la diversidad de orientaciones sexuales, así como la aceptación de las diferentes expresiones de identidad de género que permiten superar estereotipos y comportamientos sexistas, discriminatorios y violentos ${ }^{64}$. Ciertamente, las posibilidades de integración de contenidos en las distintas asignaturas y materias del currículo académico son muchas, y como se ha dicho deben acompañarse de otras medidas educativas que garanticen la transversalidad de la formación, como por ejemplo la dotación de material en bibliotecas y otras actividades e iniciativas globalizadas a nivel de centro docente ${ }^{65}$.

No obstante, la oposición a la impartición de ciertos contenidos curriculares en los que se ven implicados valores y principios constitucionales ha sido una constante en nuestro sistema educativo, sobre todo en los últimos años, aunque con poca aceptación por parte de los órganos jurisdiccionales. En efecto, han sido varios los recursos interpuestos contra la asignatura "Educación para la ciudadanía y los Derechos Humanos", implantada en el período de gobierno socialista de Rodríguez Zapatero para el último ciclo de la Educación Primaria y toda la Educación Secundaria, invocando la vulneración del derecho a la

\footnotetext{
${ }^{63}$ El principio de descentralización escolar impide a los centros escolares separarse de la tutela de la Administración competente, en la medida en que tiene unos límites naturales en un ordenamiento jurídico vinculante en que los centros solamente completan y desarrollan currícula, y en una organización administrativa regulada legal y reglamentariamente que se impone, aun con peculiaridades, a todos ellos por igual.

${ }^{64}$ Puede consultarse el Plan Director de Coeducación de la Generalitat Valenciana, diseñado como instrumento de política educativa integral y plan estratégico. En relación con las medidas curriculares, véase el Eje 3 (El currículo escolar) relativo a la revisión de los currículos académicos para conseguir el respeto a las identidades individuales y colectivas, y la diversidad sexual; y el Eje 4 (Materiales curriculares) referido a la adecuación de todo el material escolar para prevenir prejuicios sexistas y discriminatorios (pp. 14-17). El documento está accesible desde la dirección electrónica: http://www.ceice.gva.es/documents/161634256/165603089/Plan+Director+de+Coeducaci\%C3\%B3n/a53 bc1f6-e22b-4210-89aa-5e34230c4e08 (último acceso, diciembre de 2020).

${ }^{65}$ Por ejemplo, en el caso del Protocolo de atención educativa y acompañamiento al alumnado en situación de transexualidad y alumnado con expresión de género no normativa de Castilla-León (texto accesible desde la dirección: https://www.educa.jcyl.es/dpburgos/es/apebu/inclusion-orientacion-educativaabsentismo/diversidad-inclusion-educativa/documentos-varios-relacionados-atencion-diversidad-inclusio. Ultimo acceso, enero 2021), señala que deberán incluirse la diversidad de identidad o expresión de género no normativa en los diferentes documentos de centro (PEC, RRI, Plan de Orientación de Centro, Plan de Convivencia, Plan de igualdad real y efectiva entre hombres y mujeres) tanto medidas o actuaciones de atención y de visibilización, como de actuación ante situaciones de acoso adoptadas. También se desarrollarán programaciones didácticas contenidos y actividades que incluyan la realidad de la identidad de género y la forma en que se va llevará a cabo; y se dotará de recursos bibliográficos sobre la realidad LGBTI a las bibliotecas de los centros.
} 
objeción de conciencia y la libertad religiosa e ideológica ${ }^{66}$. Tampoco ha prosperado la oposición parental a ciertos contenidos curriculares vinculados a la educación sexual, invocando la vulneración del derecho a la educación reconocido en el artículo 2 del Protocolo Adicional al CEDH. Muy al contrario, ha encontrado acomodo en la jurisprudencia del Tribunal Europeo de Derecho Humanos, que ha ponderado el interés superior del menor señalando que el derecho parental a que los hijos reciban una educación de acuerdo con sus propias convicciones "no impide que los Estados puedan impartir, a través de la enseñanza, información o conocimientos que, de modo directo o indirecto, puedan tener un reflejo religioso o filosófico". Ni siquiera permite que los padres se opongan a la integración de dicha enseñanza en el currículo escolar, puesto que, de lo contrario, todo sistema institucionalizado de educación correría el riesgo de resultar impracticable ${ }^{67}$.

Más recientemente, la oposición parental se ha introducido a través de ciertas propuestas políticas que impulsan el denominado PIN Parental -expresión de origen inglés (Personal Identification Number) recogida ya en el Diccionario Panhispánico del español jurídico para referirse a una contraseña alfanumérica que permite hacer uso de ciertos aparatos o dispositivos electrónicos-, a través del cual se quiere expresar el veto parental a ciertas políticas educativas, fundamentalmente relacionadas con cuestiones sobre identidad de género, feminismo o diversidad sexual. La implantación del veto parental en nuestro país ha adquirió actualidad con motivo de la impugnación por parte del Ministerio de Educación de sendas Resoluciones de 29 de agosto de 2019, de la Secretaría General de la Consejería de Educación y Cultura de Murcia, por las que se dictan instrucciones de comienzo del curso 2019-2020 para los centros docentes que imparten Educación infantil y primaria, y Educación Secundaria Obligatoria y Bachillerato. En dichas Resoluciones se establecía que los centros docentes de la Región debían solicitar autorización expresa de las familias de los alumnos para participar en actividades complementarias, y aunque dichas actividades no se especificaban en las correspondientes Resoluciones, la introducción del veto parental respondía al compromiso político adquirido por el Partido Popular con Vox para la investidura, referido muy concretamente a la exigencia del consentimiento expreso de los padres para asistir a actividades de contenido moral o sexual. El litigio ha finalizado con el archivo de actuaciones por pérdida sobrevenida del objeto al haber concluido el curso escolar. No obstante, es de interés destacar que el TSJ de la Región de Murcia suspendió cautelarmente las resoluciones autonómicas al indicar que "existen mecanismos suficientes para que los padres expresen su no conformidad y

\footnotetext{
${ }^{66}$ En términos generales, la jurisprudencia ha señalado que los contenidos de la asignatura "Educación para la ciudadanía" no entrañan una infracción de los derechos fundamentales contenidos en los artículos 16.1 y 27.3 de la Constitución. Sobre la ausencia de lesión en la libertad ideológica y en la objeción de conciencia, véanse la STS de 11 de febrero de 2009 (rec. 948, 949 y 1013, de 2008) y la STS de 23 de septiembre de 2011 (rec. 3783/2010), entre otras muchas.

${ }^{67}$ El análisis de esta jurisprudencia, entre ellos el Caso Jiménez Alonso y Jiménez Merino c. España, puede consultarse en CLIMENT GALLART, J. A., "El pin parental y la jurisprudencia del TEDH", Actualidad Jurídica Iberoamericana, 13, 2020, pp. 102-121. Accesible desde https://idibe.org/doctrina/pin-parentalla-jurisprudencia-del-tedh (último acceso, enero 2021).
} 
que sean valoradas sus concretas razones, lo que es algo distinto de la autorización para cada actividad" 68 .

\section{3.- La formación de la comunidad educativa no universitaria}

Las Administraciones públicas han de promover acciones de formación y divulgación en materia de identidad de género, dirigidas a la comunidad educativa no universitaria (artículo 24 Ley 8/2017), como mecanismo para hacer efectivo el derecho de autodeterminación de género ${ }^{69}$. Aunque en la Comunitat Valenciana la implantación de una formación específica todavía no se ha llevado a cabo, es de interés destacar que entre las estrategias avanzadas en el mencionado Plan Director de Coeducación de la Generalitat se contempla no sólo la formación inicial del profesorado en los conocimientos y habilidades necesarias para desarrollar este plan de coeducación y que ha de adquirirse tanto en los Grados de Magisterio como en los Masters de Secundaria (Eje 1), sino también la formación permanente del profesorado (Eje 2), a través de muy distintas acciones entre las cuales se encuentra la intervención de los CEFIRE, la adecuación de la oferta de formación, con especial atención a la acción tutorial, o la oferta diferenciada de cursos o módulos en materia de diversidad sexual dirigidos a los equipos directivos, a la inspección educativa y al personal orientador escolar, entre otros colectivos $^{70}$.

\section{4.- La coordinación entre las áreas de educación, sanidad y servicios sociales}

También el protocolo ha de fijar los mecanismos de coordinación administrativa entre las distintas áreas de educación y para con la sanidad y los servicios sociales ${ }^{71}$. En relación con el ámbito educativo, especial atención merece la coordinación entre los centros

\footnotetext{
${ }^{68}$ Ante la imposibilidad de acceder a la resolución judicial desde las bases del CENDOJ, la referencia a la decisión del TSJ de Murcia la obtenemos de la nota de prensa publicada por el CGPJ desde la dirección electrónica: https://www.poderjudicial.es/cgpj/es/PoderJudicial/Tribunales-Superiores-de-Justicia/TSJRegion-de-Murcia/Sala-de-prensa/Notas-de-prensa/LaSala-de-lo-Contencioso-del-TSJMU-suspendecautelarmente-la-resolucion-autonomica-que-establece-eldenominador-veto-parental- (último acceso: 15 de febrero de 2021).

${ }^{69}$ Esta previsión ya se contempla en el Protocolo contenido en la citada Instrucción de 15 de diciembre de 2016, del Director General de Política Educativa, por la que se establece el protocolo de acompañamiento para garantizar el derecho a la identidad de género, en la que respecto de la formación en materia de identidad de género establece que "se tendrá presente en cualquier actividad académica del centro y también en las actividades complementarias y extraescolares. Para el desarrollo de las actuaciones de sensibilización, formación y acompañamiento del alumnado trans e intersexual, el centro educativo contará con el apoyo y el asesoramiento de los CEFIRE, el Servicio Psicopedagógico Escolar, los departamentos de orientación, los gabinetes psicopedagógicos municipales y con los colectivos LGTBI más representativos y registrados legalmente".

${ }^{70}$ Plan Director de Coeducación ..., pp. 10-15.

${ }^{71}$ De acuerdo con el artículo 22.2 de la Ley 8/2017, la Generalitat "coordinará los recursos del sistema educativo y sanitario con el objetivo de prevenir situaciones de riesgo que pongan en peligro el desarrollo integral y garanticen una adecuada protección al alumnado transexual, estableciendo procedimientos para garantizar un adecuado acompañamiento escolar en su proceso de afirmación, además de tutelar su paso por el sistema educativo. Al mismo tiempo, las administraciones competentes en la protección de la infancia se ocuparán de detectar, prevenir y solucionar situaciones de acoso o violencia que puedan sufrir como consecuencia de la expresión de una identidad de género no normativa o durante el proceso de transición de género".
} 
escolares y las Universidades, al objeto de facilitar la transición entre las distintas etapas educativas, así como el acceso a la Universidad.

\section{2.- La posición de las Universidades valencianas para la efectividad del derecho de autodeterminación de género}

Tras las previsiones generales en materia educativa, la Ley 8/2017 contiene ciertas disposiciones aplicables específicamente a las Universidades de la Comunidad Valenciana. Concretamente, tras encomendarles la garantía del respeto y la protección del derecho a la igualdad y no discriminación por cuestiones relacionadas con la identidad de género, la expresión de género y la diversidad sexual en cualquiera de sus manifestaciones, el artículo 25 se refiere a la adaptación del Protocolo de atención educativa a la identidad de género que la Generalitat valenciana ha de elaborar para todos los centros educativos, incluyendo medidas de seguimiento y de coordinación con los centros de acceso (artículo 25.2). Junto a este mandato, también exige a las Universidades valencianas la concreción de la actividad prestacional dirigida a la atención, protección y apoyo a los miembros de la comunidad educativa que pudieran ser objeto de discriminación por orientación sexual, identidad o expresión de género en el seno de la comunidad universitaria (párrafo segundo del artículo 25.3). Finalmente, el precepto identifica unos concretos ámbitos sobre los que la Generalitat y las Universidades han de dar cumplimiento al deber de colaboración interadministrativa, en correspondencia con las disposiciones contenidas en la legislación estatal básica, por referencia al deber de actuar con el resto de Administraciones Públicas para el logro de fines comunes, de acuerdo con el artículo 140.1 c) de la Ley 40/2015, de Régimen Jurídico del Sector Público. En concreto, se contempla la colaboración de la Generalitat dirigida a promover acciones informativas, divulgativas y formativas encaminadas a detectar, prevenir y corregir acciones de discriminación o acoso en el contexto universitario, así como evitar la impartición de contenidos discriminatorios hacia la persona por estos motivos (artículo 25.3). También se reconoce la colaboración interadministrativa para la adopción de medidas de apoyo a la realización de estudios y proyectos de investigación, así como el impulso de grupos de investigación especializados en identidad y expresión de género o la creación de una cátedra (artículo 25.4). En último lugar, el deber de colaboración se proyecta sobre la promoción de la formación e investigación en materia de identidades de género, así como el impulso a la creación y el establecimiento de unidades de atención a la diversidad por parte de las Universidades (artículo 25.5).

En términos similares, el artículo 25 de la Ley 23/2018 establece las actuaciones que las Universidades valencianas deben desarrollar para garantizar que todas las personas que conforman la comunidad universitaria puedan ejercer los derechos fundamentales amparados por la legislación autonómica, estatal e internacional, y entre ellos el derecho de autodeterminación de género en los términos que recoge la Ley 8/2017. En este concreto ámbito, el precepto contiene varios mandatos a los poderes públicos, a quienes encomienda la promoción de acciones informativas, divulgativas y formativas dirigidas a detectar, prevenir y corregir acciones de discriminación o acoso en el contexto 
universitario (artículo 25.2); así como la atención, protección y apoyo al alumnado, personal docente y personal de administración y servicios que pudiera ser objeto de discriminación por orientación sexual, identidad de género, expresión de género, desarrollo sexual o grupo familiar en el seno de la comunidad universitaria, para lo cual el precepto señala expresamente la posibilidad de crear oficinas de atención e información a las personas LGTBI (artículo 25.3). También se contempla el apoyo a la realización de estudios y proyectos de investigación sobre la situación de la diversidad sexual, de identidades y expresiones de género, familiar y de desarrollo sexual, en todas sus vertientes y ámbitos sociales, y la promoción de grupos de investigación especializados en la realidad del colectivo LGTBI (artículo 25.4).

\section{1.- La adaptación del Protocolo de atención educativa a la identidad de género por parte de las Universidades valencianas}

El artículo 25 de la Ley 8/2017 establece un mandato dirigido a las Universidades de la Comunidad Valenciana, por referencia a la adaptación del Protocolo de atención educativa a la identidad de género elaborado por la Administración autonómica para todos los centros no universitarios de acuerdo con el citado artículo 22. El efectivo cumplimiento de este precepto suscita, de inicio, varias cuestiones. En primer lugar, hemos de señalar que hasta la fecha la Consellería no ha aprobado un Protocolo en cumplimiento de las disposiciones de la Ley 8/2017 aunque, como se ha dicho, está vigente la Instrucción de 15 de diciembre de 2016, del Director General de Política Educativa, por la que se establece el protocolo de acompañamiento para garantizar el derecho a la identidad de género. Por ello, la primera de las cuestiones que debería abordarse es si el Protocolo que recoge la citada Instrucción de 2016 sirve a los efectos del artículo 22 de la Ley 8/2017, en cuyo caso se entendería por cumplido el mandato a la Administración autonómica y cuanto de ello deriva. La opción de dar por bueno el protocolo que incorpora la Instrucción de 2016 no parece encontrar ningún obstáculo de carácter sustantivo, y así parece haberse interpretado en el protocolo de atención a la identidad y expresión de género elaborado por la Universitat Politècnica de València, al mencionar expresamente esta Instrucción como disposición normativa aplicable. Y es que, en verdad, si comparamos las determinaciones que el artículo 22 de la Ley 8/2017 establece para la elaboración del protocolo con las que contiene el protocolo incorporado a la Instrucción de 2016, se comprueba la total correspondencia entre este protocolo y las determinaciones exigidas por el precepto legal. Tampoco se advierten objeciones insalvables de carácter formal pues, aunque la Ley 8/2017 exige a la Generalitat elaborar y poner al alcance de los centros educativos un protocolo de atención educativa a la identidad, nada impide que este protocolo ya se hubiera elaborado con anterioridad a la vigencia de la Ley y que, de ajustarse a los contenidos establecidos en el texto legal (cosa que ocurre en este caso), pueda servir a todos los efectos sin necesidad de un nuevo texto que, entre otras razones, consistiría en una reproducción del protocolo aprobado, de todo punto contrario a los principios de calidad normativa y buen gobierno. No obstante, no estaría de más un expreso pronunciamiento por parte de la Generalitat en el que se reconociera el valor del protocolo incorporado a la Instrucción de 2016, cuando menos 
para dotar de seguridad jurídica a la posterior intervención de las Universidades, a quienes se les encomienda la adaptación de dicho protocolo.

Por otra parte, es necesario identificar si la obligación de adaptar se proyecta sobre todas las Universidades de la Comunitat Valenciana o sólo sobre las financiadas con fondos públicos, teniendo en cuenta que el artículo 25.2 de la Ley 8/2017 se refiere a las Universidades, sin precisar que lo serán las de la Comunitat Valenciana, como sí hace el apartado primero de este precepto, y sin establecer distinción entre públicas y privadas, como ocurre en otras legislaciones autonómicas como es el caso de la Ley andaluza $8 / 2017$, de 28 de diciembre, para garantizar los derechos, la igualdad de trato y no discriminación de las personas LGTBI y sus familiares, cuyas disposiciones se aplican indistintamente a Universidades públicas y privadas. Sobre esta cuestión ya hemos señalado que, respecto de los centros docentes no universitarios de la Comunitat Valenciana, la Sentencia del TSJCV n ${ }^{\circ}$ 200/2019 ha declarado la legalidad del precepto reglamentario que disponía la exigencia de este Protocolo a los centros sostenidos con fondos públicos. Esta doctrina puede extrapolarse al ámbito de los centros universitarios, de modo que tratándose de Universidades públicas es claro que están sujetas a la adaptación del protocolo, cosa que no ocurre con las Universidades privadas cuya financiación, al quedar fuera del sistema de concierto educativo (que no se contempla en el ámbito universitario), las sitúa en una posición distinta a la que adoptan los centros privados no universitarios que se sostienen a través del concierto con fondos públicos. No obstante, la interpretación de esta regla para el caso de las Universidades privadas debería también atender los supuestos en que se percibiera cualquier tipo de financiación pública que, obviamente no responde a la idea de concierto educativo, pero que de igual modo supone un sostenimiento con fondos públicos, aunque lo sea en menor grado ${ }^{72}$.

\section{2.- Ámbitos sobre los que debe proyectarse la adaptación del Protocolo autonómico}

En los siguientes apartados avanzamos algunos de los ámbitos sobre los que las Universidades de la Comunitat Valenciana deberían realizar adaptaciones a un futuro Protocolo de atención educativa a la identidad de género aprobado por la Generalitat valenciana, así como la problemática que podría suscitarse en ellos. A tal fin, hemos agrupado el análisis por referencia a las adaptaciones subjetivas, materiales $\mathrm{y}$ procedimentales.

\subsection{1.- Adaptaciones subjetivas: La comunidad universitaria}

Uno de los ámbitos en los que claramente se advierte la necesidad de adaptación del Protocolo que de acuerdo con el artículo 22 de la Ley 8/2017 se adopte para los centros no universitarios es el relativo a los sujetos a los que será de aplicación. La comunidad educativa universitaria tiene una composición muy específica y distinta a otras

\footnotetext{
72 Podría ser, por ejemplo, el caso de la Universidad Internacional de Valencia (VIU), creada en 2008 por la Generalitat Valenciana como entidad pública, aunque en 2013, el Grupo Planeta pasó a adquirir la mayor parte del accionariado.
} 
comunidades educativas y en concreto de la no universitaria, tanto en los colectivos que la integran como en las características de alguno de ellos. De un lado, el personal docente es mucho más amplio, en la medida en que incorpora no sólo al profesorado que imparte las enseñanzas - cuya tipología es variada y sujeta a distintos regímenes jurídicos fijados en la legislación universitaria- sino también a quienes no desarrollan funciones docentes sino únicamente investigadoras en el seno de la Universidad ${ }^{73}$. También es muy distinto el alumnado universitario, fundamentalmente por su mayor edad (aunque puede haber alumnado menor durante algunos meses del curso académico), lo que además de limitar en cierto modo el ejercicio del derecho de autodeterminación ${ }^{74}$, comporta que los padres y madres no formen parte de la comunidad educativa universitaria, como sí ocurre en el ámbito de la educación no universitaria, en la que este colectivo se integra a través de las correspondientes asociaciones de madres y padres (AMPAs). Más allá de estas precisiones inherentes a la propia posición institucional de las Universidades, lo interesante a los efectos de esta exposición es que el ámbito subjetivo de aplicación del Protocolo de autodeterminación de género puede verse ampliado a consecuencia de las relaciones jurídicas en las que puede intervenir la Universidad, y de las que carecen los centros no universitarios por razón de su heterotutela o dependencia de la correspondiente Administración matriz, aun tratándose de centros educativos no universitarios que imparten enseñanzas superiores, como por ejemplo los Conservatorios Superiores de música, las Escuelas de Danza o los Centros Superiores de Artes Escénicas. La autonomía de las Universidades confiere ámbitos de actuación para con terceros que permiten una variedad de relaciones jurídicas amparadas en distintos títulos, que exceden de la autonomía de gestión reconocida a los centros docentes no universitarios. Baste señalar las posibilidades que ofrece la contratación del sector público, a través de la cual las Universidades se vinculan con terceros a los que puede ser de aplicación la regulación en materia de autodeterminación de género. También las Universidades ofrecen sus servicios a personas que no forman parte de la comunidad educativa, como por ejemplo los servicios deportivos, que de habitual se abren a toda la ciudadanía y por tanto surgen usuarios de estos servicios y de las dependencias universitarias que no son alumnado, pero a quienes también se puede extender la aplicación del Protocolo si así lo consideran las correspondientes Universidades. Claros ejemplos de extensión a estos colectivos encontramos en el Protocolo de atención a la identidad y a la expresión de género en la

\footnotetext{
73 Téngase en cuenta que, además de la Ley 6/2001, de Universidades (LOU) y de la Ley 14/2011, de 1 de junio, de la Ciencia, la Tecnología y la Innovación, en la que se establece un régimen especial para el personal investigador al servicio de las Universidades públicas, de los Organismos Públicos de Investigación y de los Organismos de investigación de otras Administraciones Públicas; las CCAA ostenta competencias para la creación de regímenes profesorales sujetos a Derecho laboral, por lo que la variedad de figuras profesorales puede ser muy amplia.

${ }^{74}$ Téngase en cuenta que la STC 99/2019, en resolución de la cuestión de inconstitucionalidad 595/2016 planteada por la Sala primera del Tribunal Supremo en relación con el artículo 1.1 de la Ley 3/2017, declara inconstitucional el precepto en la medida en que se aplica a menores de edad con suficiente madurez y que se encuentran en una situación estable de transexualidad. Un comentario crítico a dicha resolución en SALAZAR BENÍTEZ, O., "El derecho a la identidad sexual ...", al destacar que la sentencia deja sin resolver cómo y quién ha de acreditar ambos requisitos, por lo que a su juicio es necesaria una ley que regule a nivel estatal y de manera completa el derecho a la identidad sexual.
} 
Universidad de Alicante $^{75}$, y en el de la Universitat de València, por referencia a las personas usuarias de instalaciones y servicios universitarios ${ }^{76}$. En el caso de la Universitat Jaume I de Castelló, la tutela no se extiende subjetivamente pero sí existe una ampliación temporal que incluye los casos en que la relación con esta Universitat hubiera concluido a causa de una situación de acoso prevista en el Protocolo, por un plazo de seis meses desde la fecha en que acabó la mencionada relación ${ }^{77}$. Por el contrario, otras Universidades de la Comunitat Valenciana limitan su ámbito de aplicación estrictamente a la comunidad universitaria. Es el caso, por ejemplo, del Protocolo de atención a la identidad y expresión de género de la Universitat Politècnica de València ${ }^{78}$.

Ciertamente, el análisis de los distintos protocolos universitarios muestra que el ámbito subjetivo se limita a la comunidad educativa en sentido estricto cuando mantiene un enfoque exclusivamente antidiscriminatorio, en el que trata de dar respuesta fundamentalmente a las situaciones de acoso. Por el contrario, los Protocolos que superan ${ }^{75}$ Véase el artículo 5.2 y 3 del Protocolo de atención a la identidad y a la expresión de género en la
Universidad de Alicante, aprobado por acuerdo del Consejo de Gobierno de 19 de diciembre de 2017
(BOUA de 20 de diciembre), de acuerdo con el cual: "2. Cuando las actuaciones remitan a situaciones de
acoso por orientación sexual, por desarrollo sexual diferente o identidad o expresión de género divergente
(ver art. 16), y siempre que tales situaciones se den en sus relaciones con miembros de la comunidad
universitaria, este Protocolo será de aplicación: a) A las personas que presten sus servicios en la
Universidad, sea cual sea el carácter o la naturaleza jurídica de su relación con la misma. Se aplicará
también a las personas que, bajo la dependencia jurídica de un tercero, presten sus servicios en la UA, como
es el caso del personal afecto a contratas o subcontratas y/o puesto a disposición por las ETTs. b) A personas
trabajadoras autónomas contratadas por la Universidad de Alicante, o bien por otras entidades, siempre que
presten sus servicios en el ámbito propio de la Universidad. 3. Adicionalmente, cuando las actuaciones
remitan al acceso y uso de las instalaciones, el presente Protocolo será de aplicación a sus usuarias y
usuarios".

${ }^{76}$ Así lo recoge el artículo 1 del Acuerdo 138/2019, de 20 de junio, del Consejo de Gobierno, por el que se aprueba el Protocolo de atención a la identidad y a la expresión de género de la Universitat de València (DOGV de 25 de noviembre), tras fijar como ámbito subjetivo de aplicación las personas que forman parte de la comunidad universitaria, y en especial de aquellas que, en el ámbito universitario, manifiestan una identidad de género sentida diferente de la asignada en el momento del nacimiento. Adicionalmente, cuando las actuaciones remiten al acceso y el uso de instalaciones y servicios universitarios, este protocolo será aplicable también a las personas usuarias de éstos.

77 Véase el artículo 2 del Protocolo para la detección, prevención y actuación en los supuestos de acoso laboral, acoso sexual, acoso por razón de sexo, acoso por orientación sexual e identidad y expresión de género en la Universitat Jaume I de Castelló (aprobado por el Consejo de Gobierno en la sesión de 26 de octubre de 2017), en el que se dispone: “Artículo 2. Ámbito de aplicación. 1. Este protocolo es aplicable a la totalidad de las personas que integran la comunidad universitaria, es decir, al personal de administración y servicios (PAS), al personal docente e investigador (PDI), a los becarios y becarias, al alumnado y a cualquier persona que, incluso bajo la dependencia jurídica de un tercero, preste sus servicios en el ámbito de la Universitat Jaume I (en este último caso, siempre que la parte denunciada en la controversia sea miembro de la comunidad universitaria). 2. Además, quedará bajo el amparo del presente protocolo cualquier persona comprendida en el apartado 1, cuya relación con la Universitat Jaume I hubiera concluido (bajo cualquier forma jurídica) a causa de una situación de acoso prevista en este Protocolo, y que invocó el presente procedimiento en un plazo de seis meses desde la fecha en que acabó la mencionada relación". ${ }^{78}$ El artículo 2 del Protocolo de atención a la identidad y expresión de género de la Universitat Politècnica de València (aprobado por el Consejo de Gobierno en su sesión de 26 de abril) establece: "Este protocolo es de aplicación a cualquier miembro de la comunidad universitaria en sus actividades y actuaciones sin alterar la titularidad jurídica de los derechos y obligaciones que correspondan a esa persona y sin prescindir del número del documento nacional de identidad o del documento de equivalente validez legal (NIE, pasaporte), siempre que dicho número deba figurar". 
este enfoque suelen ampliar su ámbito subjetivo, en correspondencia con los ámbitos de libertad sobre los que se proyecta la autodeterminación de género.

\subsection{2.- Adaptación material del Protocolo}

También será necesaria la adaptación de los ámbitos sobre los que se proyecta el Protocolo, en correspondencia con la posición de las Universidades como sujetos obligados a la prestación del servicio de la educación superior. En este punto, tal como exige la Ley 8/2017, la tutela del derecho de autodeterminación de género ha de ser integral y por tanto incorporar no sólo acciones preventivas ${ }^{79}$, sino también de reconocimiento o tutela del derecho de autodeterminación (por ejemplo en relación con la adecuación del nombre y la documentación administrativa correspondiente), de fomento en su más amplia extensión (acompañamiento, asesoría...), prestacionales (adecuación de espacios e instalaciones, deporte universitario....), sancionadoras y formativas para con toda la comunidad educativa. Las Universidades de la Comunitat Valenciana no son ajenas al modelo universitario de atención de la diversidad afectivosexual, articulado sobre la base de dos temáticas: el acoso sexual y el cambio de nombre. Así, mientras algunas Universidades responden a una posición claramente antidiscriminatoria, en la que fundamentalmente se trata de dar respuesta a las situaciones de acoso y por tanto se recurre al Derecho administrativo sancionador, aunque en algunos casos también se introduce el recurso a la mediación ${ }^{80}$. Por el contrario, otras Universidades han optado por implementar protocolos sectoriales, fundamentalmente para la fijación del procedimiento y efectos del cambio de nombre ${ }^{81}$, aunque en su mayoría la opción escogida por las Universidades valencianas es la apuesta por la tutela integral de la identidad de género, no enfocada fundamentalmente a la sanción antidiscriminatoria del acoso, incorporando junto a la regulación del cambio de nombre de uso común, adaptaciones curriculares, mecanismos de acceso y uso de los espacios comunes como los vestuarios y aseos, y toda una serie de medidas docentes, investigadoras y formativas dirigidas a sensibilizar frente a la realidad LGTBI ${ }^{82}$.

\footnotetext{
${ }^{79}$ De especial interés resulta la puesta a disposición de mecanismos alternativos de resolución de conflictos, en línea con los planes de convivencia.

${ }^{80}$ Es el caso, por ejemplo, del Protocolo para la detección, prevención y actuación en los supuestos de acoso laboral, acoso sexual, acoso por razón de sexo, acoso por orientación sexual e identidad y expresión de género en la Universitat Jaume I de Castellón, aprobado por el Consejo de Gobierno en la sesión de 26 de octubre de 2017. Además de la incoación del procedimiento disciplinario correspondiente, es posible la reconducción de los hechos a través de un procedimiento de mediación ante la Sindicatura de Agravios, sin perjuicio de la intervención de la jurisdicción penal. En relación con el acoso por razón de identidad de género, el Protocolo incorpora como ejemplos de conductas sancionables las siguientes: Negarse a llamar una persona trans como requiere o utilizar deliberadamente artículos o pronombres no correspondientes al género con que se identifica; Expulsar y/o cuestionar a las personas con expresiones o identidades de género no normativas por estar en un baño/vestuario determinado; Menospreciar las capacidades, las habilidades y el potencial intelectual de la persona con relación a expresión o identidad de género; y Utilizar humor tránsfobo o intérfobo.

${ }^{81}$ Es el caso del Protocolo para el cambio de nombre de personas transexuales, transgénero e intersexuales en la Universidad Miguel Hernández de Elche, aprobado en sesión del Consejo de Gobierno de 25 de octubre de 2017.

${ }^{82}$ Véanse, por ejemplo, el Protocolo de atención a la identidad y a la expresión de género en la Universidad de Alicante, aprobado por Consejo de Gobierno de 19 de diciembre de 2017; el Protocolo de atención a la
} 
En todo caso, no podemos obviar la importancia del posicionamiento institucional de la Universidad, su papel como transformador de la realidad social en materia de género, que expresa la responsabilidad social de la Universidad pública en la garantía del derecho de autodeterminación ${ }^{83}$. Algunas Universidades, como por ejemplo la Universitat Jaume I de Castelló incorporan este posicionamiento a través de la proclamación de principios que son fundamento y guía de su actuación (tolerancia cero frente a la violencia, física o psíquica, ejercida en el ámbito de la comunidad universitaria) ${ }^{84}$. Esta misma posición institucional se expresa a través de la visibilización del colectivo LGTBI en determinados actos conmemorativos, como por ejemplo el día del orgullo, en los que muchas Universidades cuelgan la bandera arcoíris en sus sedes oficiales y en otros espacios; aunque como sabemos, se trata de una decisión no exenta de polémica cuando menos para las Universidades públicas, después de que el Tribunal Supremo declarase que las Administraciones no pueden legalmente exhibir otras banderas que no sean las oficiales ${ }^{85}$.

\subsection{3.- Adaptación procedimental}

Otro de los ámbitos necesitados de adaptación es el procedimental, en la medida en que las Universidades gozan de autonomía para fijar sus propias normas de organización y funcionamiento. En materia de autodeterminación de género, la Ley exige la adaptación del protocolo aprobado por la Administración autonómica, para lo cual las Universidades deben adoptar sus propias disposiciones, cuya identificación con el término comúnmente utilizado de Protocolo, no debe conducir a error en su naturaleza jurídica reglamentaria ${ }^{86}$. Y es que, pese a las dificultades que en la práctica suele ofrece el deslinde entre norma reglamentaria e instrucción u orden de servicio, tanto por su contenido normativo y de desarrollo de las disposiciones legales en materia de autodeterminación como por los efectos ad extra que produce y por las formalidades seguidas para su aprobación, la adaptación que las Universidades hagan del Protocolo elaborado por la Generalitat no es

identidad y a la expresión de género de la Universitat de València, aprobado por Acuerdo 138/2019, de 20 de junio, del Consejo de Gobierno; o el Protocolo de atención a la identidad y expresión de género de la Universitat Politècnica de València, aprobado por el Consejo de Gobierno en su sesión de 26 de abril de 2018.

${ }^{83}$ En su mayoría las Universidades públicas han manifestado expresamente su compromiso institucional con la autodeterminación de género. Véase, por ejemplo, el Protocolo de no discriminación y contra el acoso por razón de orientación sexual e identidad de género y/o pertenencia a grupo familiar LGTBI de la Universidad de Cádiz, aprobado por Acuerdo del Consejo de Gobierno de 26 de marzo de 2019, y cuyo artículo 3 recoge expresamente el compromiso contra la discriminación por LGTBIfobia. También el Protocolo para el cambio de nombre de las personas con identidad transgénero en la Universidad de Oviedo, en el apartado IV, dedicado a las "Acciones de difusión y apoyo en el contexto universitario" reconoce expresamente "un compromiso claro contra las actitudes de discriminación por homofobia, lesbofobia, bifobia o transfobia" (accesible desde https://igualdad.uniovi.es/cambionombre).

${ }^{84}$ Véase, por ejemplo, el Preámbulo del Protocolo de la Universitat Jaume I de Castelló, en el que expresamente se recogen los principios rectores y los compromisos institucionales de la Universitat para con cualquier tipo de acoso.

${ }^{85}$ Véase la STS n ${ }^{\circ}$ 564/2020, de 26 de mayo (rec. no 1327/2018).

${ }^{86}$ En este caso, el término no responde al concepto de protocolo general de actuación que, de acuerdo con el artículo 47.1 de la Ley 40/2015 comporta meras declaraciones de intención de contenido general o que expresen la voluntad de las Administraciones y partes suscriptoras para actuar con un objetivo común, siempre que no supongan la formalización de compromisos jurídicos concretos y exigibles. 
otra cosa que la expresión de la potestad normativa de que gozan en garantía de su autonomía institucional (artículo 2.2 LOU). Con ello no se niega la posibilidad de que el Protocolo contenga disposiciones de soft law, no vinculantes, e incluso un contenido no normativo que, por ejemplo, contribuya al entendimiento y aplicación o interpretación de las disposiciones normativas, como ocurre en el caso de la Universitat de València ${ }^{87}$. Pero ninguna de estas circunstancias altera la naturaleza reglamentaria del Protocolo aprobado y cuanto de ello pueda derivarse, concretamente en relación con los límites a los que se someten las potestades normativas que puede ejercer la Universidad ${ }^{88}$.

En este punto, la Ley encomienda a las Universidades de la Comunitat Valenciana una tarea muy concreta, referida a la "adaptación" del documento previamente aprobado por la Generalitat. Y lo singular es que no existe una remisión de la Ley al desarrollo reglamentario por parte de las Universidades, propia del tradicional reenvío de la ley al reglamento secundum legem, sino un reenvío a que las Universidades desarrollen el reglamento aprobado por la Administración autonómica a través de la aprobación del Protocolo de atención educativa a la identidad de género a que nos hemos referido en los apartados anteriores. En este caso, la potestad normativa de las Universidades se ve intermediada por la exigencia de una previa actuación regulatoria de la Administración autonómica, y no directamente en desarrollo de la Ley. Dicho de otro modo, existe una llamada a la potestad reglamentaria de la Universidad, no para el desarrollo de la Ley sino del reglamento que apruebe la Generalitat; una llamada al reglamento "de segundo grado" que sólo puede entenderse respetuosa con la autonomía universitaria en la medida en que no se impida a las Universidades hacer pleno uso de su capacidad normativa ${ }^{89}$, sin perjuicio de la adaptación del Protocolo que se considere conveniente para dar cumplimiento a las disposiciones de la Ley 8/2017.

En verdad, no se adivinan los motivos por los cuales, para el caso del derecho de autodeterminación de género, la Ley 8/2017 introduce la referencia a una "adaptación" del Protocolo adoptado por la Administración autonómica; cosa que no contienen otras legislaciones autonómicas en materia de identidad de género, ni tampoco ocurre en otros ámbitos como por ejemplo la violencia de género o el acoso, sobre los cuales las Universidades han aprobado sus propios Protocolos en desarrollo de las previsiones

\footnotetext{
${ }^{87}$ El Protocolo de atención a la identidad y a la expresión de género de la Universitat de València, aprobado por Acuerdo del Consejo de Gobierno 138/2019, de 20 de junio, se acompaña de un documento titulado Informe explicativo, accesible desde: https://www.uv.es/uvweb/unitat-igualtat/ca/diversitats-/diversitats/arees-treball/acompanyament-atencio-diversitat-1286056192562.html (último acceso, noviembre de 2020).

${ }^{88}$ Sobre la potestad normativa de las Universidades, AGUIRRE i FONT, J. M., "Los límites de las Universidades en la aprobación de reglamentos", Organización de la Universidad y la Ciencia, LÓPEZ RAMÓN, F., RIVERO ORTEGA, R. y FERNANDO PABLO, M. M. (Coords.), INAP, 2018, pp. 735-746. En la misma obra, CUETO PÉREZ, M., "Potestad normativa de las universidades públicas", pp. 529-560. ${ }^{89}$ La autonomía universitaria, en tanto derecho fundamental, tiene un contenido esencial (artículo 53.1 CE), que condiciona el desarrollo legislativo y por tanto no puede ser rebasado o desconocido por el legislador introduciendo sometimientos y limitaciones. El TC ha identificado ese contenido esencial con las potestades enumeradas de forma sucesiva por el artículo 3.2 de la LRU (SSTC 26/1987, 55/1989, 106/1990, 130/1991, 187/1991, 156/1994 y 75/1997, entre otras), que se corresponde con el actual artículo 2.2 de la Ley Orgánica, 6/2001, de 21 de diciembre, de Universidades.
} 
contenidas en la correspondiente Ley, sin necesidad de adaptar los adoptados por la Administración educativa competente para los centros no universitarios. Quizá lo que la Ley $8 / 2017$ ha querido señalar con la expresión "adaptación" es la necesidad de articular mecanismos de coordinación, tanto con la Generalitat como con los centros docentes de cuyo alumnado se va a nutrir la Universidad tras la superación de las pruebas de acceso a la Universidad, y sin duda con otros ámbitos de actuación administrativa, como el sanitario o el social. Pero lo cierto es que la referencia a una adaptación poco añade a la posición institucional que ostentan las Universidades en desarrollo del derecho de autodeterminación. Tan es así que, pese a que la Generalitat no ha aprobado un Protocolo de atención educativa a la identidad de género en cumplimiento de los mandatos del artículo 22 de la Ley 8/2017 (aunque existe una Instrucción de 15 de diciembre de 2016 a la que hemos hecho referencia, y que algunas Universidades valencianas han tomado con norma autonómica vinculante $)^{90}$, las Universidades valencianas han ido aprobando sus propios Protocolos para la tutela de la identidad de género. Bien es cierto que estos Protocolos también encuentran anclaje en la legislación estatal contenida en la Ley Orgánica 3/2007, para la igualdad efectiva de mujeres y hombres ${ }^{91}$, y en la Ley 3/2007, reguladora de la rectificación registral de la mención relativa al sexo de las personas; así como en otras disposiciones autonómicas como puede ser la Ley 9/2003, de 2 de abril, para la igualdad entre mujeres y hombres. Aun así, lo importante a reseñar es que la ausencia de una regulación previa por parte de la Generalitat no es obstáculo para el ejercicio de la potestad reglamentaria por parte de las Universidades, aunque obviamente sí puede verse afectada o temporalmente condicionada por una futura regulación autonómica, sobre la cual deberá realizar las correspondientes "adaptaciones". En todo caso, la adaptación que las Universidades deban realizar respecto del Protocolo que se adopte por la Administración autonómica, tanto en los contenidos o ámbitos sobre los que debe proyectarse la adaptación como en el momento en que las Universidades hagan uso de esta potestad, no puede suponer una injerencia en la capacidad normativa que la LOU reconoce a las Universidades, pues lo contrario supondría una violación de la autonomía universitaria.

Por otra parte, las adaptaciones procedimentales que se adopten se han de proyectar sobre la estructura organizativa propia de cada Universidad. Así, todas las referencias a la responsabilidad del equipo directivo que se contienen en el Protocolo aprobado por la Instrucción del 15 de diciembre de 2016 o en la norma que apruebe la Generalitat de acuerdo con el artículo 22 de la Ley 8/2017, han de adecuarse a la estructura universitaria establecida en la LOU, en los correspondientes Estatutos universitarios y en las normas de régimen interior, de acuerdo con las cuales existen amplias posibilidades en manos de

\footnotetext{
${ }^{90}$ Es el caso del mencionado Protocolo de atención a la identidad y expresión de género de la Universitat Politècnica de València, aprobado por el Consejo de Gobierno en su sesión de 26 de abril de 2018.

${ }^{91}$ Téngase en cuenta que los Protocolos específicos de prevención y actuación frente al acoso sexual y por razón de sexo en las Universidades Públicas son normas reglamentarias que establecen pautas de actuación específicas frente a conductas que lesionan derechos fundamentales y que se articulan siguiendo el mandato del artículo 62.1 de la LOI. Sobre el carácter normativo de estos Protocolos, ALMODÓVAR IÑESTA, M., "Algunas cuestiones técnico jurídicas ....", pp. 15-50.
} 
cada una de las Universidades, siempre que se respete el contenido esencial del derecho fundamental (artículo 27.10 CE). Por tanto, no existe intervención de la inspección educativa, propia de las etapas no universitarias, sin perjuicio de la competencia de la Alta Inspección (artículos 148 y siguientes LOE); y cobran especial relevancia las Unidades de Igualdad $^{92}$, creadas como parte de las estructuras universitarias con la misión de desarrollar funciones relacionadas con el principio de igualdad entre mujeres y hombres (Disposición Adicional Duodécima de la Ley Orgánica 4/2007, de 12 de abril, de modificación de la LOU), aunque nada impide la creación de específicas estructuras organizativas en materia de autodeterminación de género, si así lo considera la correspondiente Universidad ${ }^{93}$.

De igual modo, la tramitación del procedimiento para la activación del protocolo ha de sufrir adaptaciones procedimentales derivadas de la distinta organización administrativa y de la competencia atribuida a los correspondientes órganos universitarios. Aunque no detenemos la atención en las concretas adaptaciones procedimentales que pueden articularse para hacer efectivo el derecho de autodeterminación, sin duda la consolidada aplicación de Protocolos contra la violencia de género es un claro referente para la adecuada adaptación ${ }^{94}$ y sobre todo para hacer frente a los problemas que en su aplicación se han identificado como por ejemplo las deficiencias referidas a la duración de la tramitación ${ }^{95}$, el respeto a las garantías procedimentales (diligencia y celeridad, imparcialidad) o las dificultades derivadas del cumplimiento de los deberes de sigilo y confidencialidad que deben respetar cuantos intervengan en el correspondiente procedimiento y que, en el caso del ejercicio de potestades sancionadoras, han de ser mucho más exigentes, si cabe.

\section{3.- El deber de colaboración}

El artículo 25 de la Ley 8/2017 establece los distintos ámbitos sobre los que la Generalitat y las Universidades han de dar cumplimiento al deber de colaboración interadministrativa para el cumplimiento de los fines comunes en materia de identidad de género.

\footnotetext{
${ }^{92}$ De especial interés resulta el estudio de TORRES PARRA, M ${ }^{\mathrm{a}} \mathrm{J}$., "Fortalezas y debilidades de los protocolos antiacoso: el papel de las unidades de igualdad en la resolución de denuncias de acoso", XI Encuentro de Unidades de Igualdad de las Universidades españolas. Buenas prácticas en igualdad de género (Universidade da Coruña, 24-25 de mayo 2018), LÓPEZ DÍAZ, A. J. (Coord.), Universidade da Coruña, Servizo de Publicacións, 2019. DOI: https://doi.org/10.17979/spudc.9788497497732.

${ }^{93} \mathrm{La}$ variedad de formas organizativas para la atención de la diversidad sexual está en correspondencia con los ámbitos de autonomía universitaria. Mucho antes de la creación de las Unidades de Igualdad, algunas Universidades habían diseñado estructuras específicas. Por ejemplo, en 1997, la Universidad del País Vasco fue pionera en la creación de la Unidad de Orientación Psicosexual, y en 2016, la Universidad Complutense de Madrid creó la Oficina de Diversidad Sexual e Identidad de Género.

${ }^{94}$ BIGLIA, B. y CAGLIERO, S., "Abordajes y "respuestas" de las universidades catalanas frente a las violencias LGTBIQ+fóbicas", Quaderns de Psicología, Vol 21, 2, 2019, p. 10, señalan que el hecho de proponer el mismo procedimiento contra las violencias sexuales y los ataques LGTBIQ+fóbicos podría ser el resultado de asumir que estas violencias comparten una raíz común.

${ }^{95}$ CAGLIERO, S. y BIGLIA, B., "Políticas sobre violencias y abusos sexuales en las universidades catalanas", Revista Española de Ciencia Política, 50, 2019, pp. 141-170, señalan que aunque los protocolos establecen un tiempo máximo para resolver los procedimientos, las entrevistadas apuntan a que en las pocas ocasiones que se han activado, las actuaciones institucionales han sido lentas, opacas y escasamente empáticas con las persones denunciantes (p. 153).
} 
Concretamente, el precepto proyecta la colaboración sobre tres ámbitos: la promoción de acciones informativas, divulgativas y formativas; la adopción de medidas de apoyo a la realización de estudios y proyectos de investigación sobre identidad de género; y la promoción de la formación e investigación en materia de identidades de género, así como el impulso a la creación y el establecimiento de unidades de atención a la diversidad por parte de las Universidades. Ciertamente se trata de tres ámbitos en los que la Generalitat y las Universidades tienen fines comunes. Muchas de las acciones que las Universidades pueden desarrollar en relación con las enseñanzas que imparten requieren de la autorización o aprobación de la Administración autonómica para su puesta en marcha (pensemos, por ejemplo, en la autorización para la impartición de nuevos títulos oficiales) o bien de la acción de fomento o subvencional, pues no olvidemos que las acciones de promoción, como parte de la actividad de fomento pueden realizarse por todas las Administraciones que ostenten competencia sustantiva sobre la materia (en este caso educativa) sin que por ello se invadan las competencias atribuidas a cada centro de poder. También existen competencias compartidas en relación con la formación e investigación, que no invadirían la autonomía universitaria en la medida en que la Generalitat desarrolla acciones subvencionales y otro tipo de actividades de fomento en el ámbito formativo y de la investigación.

\section{CONCLUSIONES}

El análisis del derecho de autodeterminación de género en el ámbito educativo nos permite mostrar una superación del tradicional enfoque discriminatorio en favor de un tratamiento integral, aunque la conformación de un verdadero derecho subjetivo todavía encuentra serias dificultades, y no sólo jurídicas. La indefinición y constante evolución de conceptos metajurídicos necesarios para articular un marco normativo, la ausencia de un modelo de Derecho comparado que pueda trasladarse fácilmente a nuestro ordenamiento y la intrincada distribución de competencias, propia de nuestro Estado descentralizado son algunos de los inconvenientes que deben superarse para la conformación de un marco normativo adecuado a las actuales necesidades de las personas LGTBI.

A nivel estatal no puede obviarse la trascendencia que tuvo la Ley 3/2007, de 15 de marzo, reguladora de la rectificación registral de la mención relativa al sexo de las personas, aunque el estudio muestra claramente que son las legislaciones autonómicas las que han impulsado un marco normativo superador del enfoque discriminatorio, en favor de un tratamiento integral de la autodeterminación de género, haciendo uso de muy distintos títulos competenciales asumidos estatutariamente. Nuestro análisis se detiene en la competencia autonómica en materia educativa, mostrando las posibilidades que ofrecen de los mecanismos regulatorios a través de las disposiciones contenidas en la Ley valenciana 8/2017, de 7 de abril, integral del reconocimiento del derecho a la identidad y a la expresión de género. El expreso reconocimiento de un derecho subjetivo de autodeterminación de género, conformado por un amplio haz de facultades pese a las 
limitaciones que impone la competencia estatal expresada en la Ley $3 / 2007$, es el punto de partida para el diseño de un conjunto de políticas públicas encaminadas a hacer efectivo este derecho en el ámbito educativo. Entre los distintos mecanismos de intervención administrativa que se mencionan se encuentra la elaboración de un protocolo por parte de la Administración autonómica, concebido como instrumento vinculante para la tutela integral de la autodeterminación de género, y por tanto con fuerza normativa para garantizar su efectiva implantación en todos los centros docentes sostenidos con fondos públicos. El protocolo se muestra como una superación de los planes de convivencia escolar, muy adecuados como documentos de soft law al servicio de la prevención de riesgos y regulación de la convivencia escolar, pero insuficientes para la garantía de la autodeterminación de género. Este mecanismo de Derecho blando, implantado en los distintos niveles escolares, se sustituye ahora por un protocolo diseñado como instrumento con un mayor grado de vinculación jurídica, hasta el punto de exigir a las Universidades la implementación de las correspondientes adaptaciones, sin que por ello se vea afectada la autonomía universitaria constitucionalmente reconocida. Desde esta premisa, el estudio avanza los distintos ámbitos sobre los que debe proyectarse esta adaptación por parte de las Universidades, mostrando las posibilidades de una ampliación en el ámbito subjetivo de aplicación, que va más allá de la comunidad universitaria en sentido estricto (PDI, alumnado y PAS), admitiendo su extensión a personas con las que las Universidades se relacionan en virtud de distintos y muy variados títulos jurídicos (usuarios de servicios universitarios, concesionarios, contratistas...). También la adaptación permite a las Universidades una ampliación en el ámbito objetivo, superador del tradicional enfoque antidiscriminatorio, incidiendo en una tutela mucho más amplia que facilite todo un conjunto de medidas docentes, investigadoras y formativas. Por último, se han hecho las oportunas propuestas para la implementación de los ajustes procedimentales y orgánicos, en correspondencia con la posición institucional que ocupan las Universidades, no sólo como encargadas de la educación superior sino también por la responsabilidad social que como tales asumen en nuestra sociedad.

\section{BIBLIOGRAFÍA}

AGUIRRE i FONT, J. M., "Los límites de las Universidades en la aprobación de reglamentos", Organización de la Universidad y la Ciencia, LÓPEZ RAMÓN, F., RIVERO ORTEGA, R. y FERNANDO PABLO, M. M. (Coords.), INAP, 2018, pp. 735 746.

ALMODÓVAR IÑESTA, M., “Algunas cuestiones técnico jurídicas sobre los protocolos contra el acoso sexual y por razón de sexo en las Universidades Públicas", Revista Andaluza de Administración Pública, 99, 2017, pp. 15-50.

ALVAREZ RODRIGUEZ, I., "La Organización de las Naciones Unidas y el derecho a la no discriminación por motivo de orientación sexual e identidad de género: apuntes para un debate", Revista General de Derecho Constitucional, 17, 2013. 
ALVENTOSA DEL RIO, J., "La regulación de la identidad de género en las Comunidades Autónomas", Instituto de Derecho Iberoamericano (IDIBE), 3 de abril de 2015. Accesible desde https://idibe.org/cuestiones-de-interes-juridico/la-regulacion-dela-identidad-de-genero-en-las-comunidades-autonomas/.

ARAGON REYES, M., "Nota Introductoria", Revista General de Derecho Constitucional, 17, 2013, pp. 1-4.

BALAGUER CALLEJÓN, F., "Derechos, principios y objetivos relacionados con la igualdad de género", Reformas estatutarias y Declaraciones de derechos, Instituto Andaluz de Administración Pública, BALAGUER CALLEJÓN, F. (Dir.), Sevilla, 2008.

BARRERO ORTEGA, A., Nuevos derechos y garantías, Tirant lo Blanch, Valencia, 2019.

BELDA PÉREZ-PEDRERO, E., “Transexualidad y Derechos Fundamentales: protección integral sin la utilización del factor sexo como diferencia”, Cuadernos de Derecho Público, 21, 2004, pp. 127-161.

BIGLIA, B. y CAGLIERO, S., “Abordajes y "respuestas” de las universidades catalanas frente a las violencias LGTBIQ+fóbicas", Quaderns de Psicología, Vol. 21, 2, 2019, pp. $1-10$.

CLIMENT GALLART, J. A., "El pin parental y la jurisprudencia del TEDH”, Actualidad Jurídica Iberoamericana, 13, 2020, pp. 102-121. Accesible desde https://idibe.org/doctrina/pin-parental-la-jurisprudencia-del-tedh/ último acceso, enero 2021.

CUETO PÉREZ, M., "Potestad normativa de las universidades públicas", Organización de la Universidad y la Ciencia, LÓPEZ RAMÓN, F., RIVERO ORTEGA, R. y FERNANDO PABLO, M. M. (Coords.), INAP, 2018, pp. 529-560.

DÍAZ CREGO, M., “Administraciones Públicas españolas y Derechos del colectivo LGTBI”, Revista General de Derecho Constitucional, 17, 2013.

DÍAZ LAFUENTE, J., "La protección de los Derechos fundamentales frente a la discriminación por motivos de orientación sexual e identidad de género en la Unión Europea", Revista General de Derecho Constitucional, 17, 2013.

ELVIRA PERALES, A., "Transexualidad y Derechos", Revista General de Derecho Constitucional, 17, 2013.

FLORES SALAZAR, A. L, "El Registro Civil soporte del derecho a la identidad. Las personas trans y el reconocimiento de la identidad de género", Revista de Derecho Electoral, 25, 2018, pp. 215-231.

GALERA VICTORIA, A., "La actividad legislativa en materia de igualdad efectiva entre mujeres y hombres", Investigación y género. Inseparables en el presente y en el futuro: IV Congreso Universitario Nacional "Investigación y Género". Sevilla, 21 y 22 de junio de 2012, VÁZQUEZ BERMÚDEZ, I. (Coord.), 2012, pp. 567-590. 
GARCÍA MESEGUER, A., "Género y sexo en el nuevo Diccionario de la Real Academia", Política científica, 37, 1993, pp. 51-56.

LAGUNA DE PAZ, J. C., "Regulación, externalización de actividades administrativas y autorregulación”, Revista de Administración Pública, 185, 2011, pp. 89-112.

LAUROBA LACASA, E., "Las personas intersexuales y el derecho: posibles respuestas jurídicas para un colectivo invisible", Derecho Privado y Constitución, 32, 2018, pp. 1154. Disponible en: https://doi.org/10.18042/cepc/dpc.32.01.

LÓPEZ-GALIACHO PERONA, J., La problemática jurídica de la transexualidad, McGraw-Hill, Madrid, 2000.

MALDONADO, J., "El reconocimiento del derecho a la identidad sexual de los menores transexuales en los ámbitos registral, educativo y sanitario", Revista Jurídica de la Universidad Autónoma de Madrid, 36, 2017-II, pp. 135-169.

MEDINA ALCOZ, L., "Historia del concepto de derecho subjetivo en el Derecho Administrativo español", Revista de Derecho Público: Teoría y Método, Vol. 1, 2021, pp. 7-52.

MONEREO ATIENZA, C., "Aproximación conceptual a la orientación sexual e identidad de género: Estrategias político-jurídicas para la reivindicación de derechos del colectivo de LGBT", Aportaciones a la investigación sobre mujeres y género: $V$ Congreso Universitario Internacional "Investigación y Género, Sevilla, 3 y 4 de julio de 2014, 2015, pp. 1231-1248. Accesible desde https://idus.us.es/handle/11441/41135. Último acceso, diciembre 2020).

MUÑOZ MACHADO, S., Tratado de Derecho administrativo y Derecho Público General. Tomo XIV. La actividad regulatoria de la Administración, Editorial BOE, 2015.

NANCLARES VALLE, J., "Comentario a la Sentencia del Tribunal Supremo de 6 de septiembre de 2002: una recepción incompleta de la nueva doctrina del Tribunal Europeo de Derechos Humanos en materia de transexualidad", Repertorio Aranzadi del Tribunal Constitucional, 12, 2003, pp. 2609-2644.

PLATERO MÉNDEZ, R., "Transexualidad y agenda política: una historia de (dis)continuidades y patologización”, Política y sociedad, Vol. 46, 1-2, 2018, pp. 107128.

RUBIO MARÍN, R. y OSELLA, S., "El nuevo derecho constitucional a la identidad de género entre la libertad de elección, el incremento de categorías y la subjetividad y fluidez de sus contenidos. Un análisis desde el derecho comparado", Revista española de derecho constitucional, 118, 2020, pp. 45-75.

SALAZAR BENÍTEZ, O., "La identidad de género como derecho emergente", Revista de Estudios Políticos, 169, 2015, pp. 75-107. Accesible desde: https://doi.org/10.18042/cepc/rep.169.03 (último acceso diciembre 2020). 
SALAZAR BENÍTEZ, O., "El derecho a la identidad sexual de las personas menores de edad. Comentario a la STC 99/2019, de 18 de julio de 2019”, Revista de Derecho Constitucional Europeo, 32, 2019.

SALAZAR BENÍTEZ, O., "El reconocimiento jurídico-constitucional de la diversidad afectiva y sexual”, Revista de estudios políticos, 157, 2012, pp. 45-81.

TORRES PARRA, M ${ }^{\mathrm{a}} \mathrm{J}$., "Fortalezas y debilidades de los protocolos antiacoso: el papel de las unidades de igualdad en la resolución de denuncias de acoso", XI Encuentro de Unidades de Igualdad de las Universidades españolas. Buenas prácticas en igualdad de género (Universidade da Coruña, 24-25 de mayo 2018), LÓPEZ DÍAZ, A. J. (Coord.), Universidade da Coruña, Servizo de Publicacións, 2019. DOI: https://doi.org/10.17979/spudc.9788497497732.

TUBERT, S., Del sexo al género: los equívocos de un concepto, Cátedra, 2003.

VILLALBA SÁNCHEZ, A., "Los protocolos de prevención y actuación frente al acoso por razón de género en las universidades pertenecientes a la Comunidad Autónoma de Galicia", Dereito, Vol. 28, 1, 2019, pp. 179-207. 